\title{
Bypass surgery for complex middle cerebral artery aneurysms: an algorithmic approach to revascularization
}

\author{
Ali Tayebi Meybodi, MD, ${ }^{1,2}$ Wendy Huang, MD, PhD, ${ }^{1}$ Arnau Benet, ${ }^{1,2}$ MD, Olivia Kola, ${ }^{2}$ and \\ Michael T. Lawton, MD ${ }^{1,2}$ \\ 1Department of Neurosurgery and ${ }^{2}$ Skull Base and Cerebrovascular Laboratory, University of California, San Francisco, \\ California
}

OBJECTIVE Management of complex aneurysms of the middle cerebral artery (MCA) can be challenging. Lesions not amenable to endovascular techniques or direct clipping might require a bypass procedure with aneurysm obliteration. Various bypass techniques are available, but an algorithmic approach to classifying these lesions and determining the optimal bypass strategy has not been developed. The objective of this study was to propose a comprehensive and flexible algorithm based on MCA aneurysm location for selecting the best of multiple bypass options.

METHODS Aneurysms of the MCA that required bypass as part of treatment were identified from a large prospectively maintained database of vascular neurosurgeries. According to its location relative to the bifurcation, each aneurysm was classified as a prebifurcation, bifurcation, or postbifurcation aneurysm.

RESULTS Between 1998 and 2015, 30 patients were treated for 30 complex MCA aneurysms in 8 (27\%) prebifurcation, $5(17 \%)$ bifurcation, and $17(56 \%)$ postbifurcation locations. Bypasses included 8 superficial temporal artery-MCA bypasses, 4 high-flow extracranial-to-intracranial (EC-IC) bypasses, 13 IC-IC bypasses $(6$ reanastomoses, 3 reimplantations, 3 interpositional grafts, and 1 in situ bypass), and 5 combination bypasses. The bypass strategy for prebifurcation aneurysms was determined by the involvement of lenticulostriate arteries, whereas the bypass strategy for bifurcation aneurysms was determined by rupture status. The location of the MCA aneurysm in the candelabra (Sylvian, insular, or opercular) determined the bypass strategy for postbifurcation aneurysms. No deaths that resulted from surgery were found, bypass patency was $90 \%$, and the condition of $90 \%$ of the patients was improved or unchanged at the most recent follow-up.

CONCLUSIONS The bypass strategy used for an MCA aneurysm depends on the aneurysm location, lenticulostriate anatomy, and rupture status. A uniform bypass strategy for all MCA aneurysms does not exist, but the algorithm proposed here might guide selection of the optimal EC-IC or IC-IC bypass technique.

https://thejns.org/doi/abs/10.3171/2016.7.JNS16772

KEY WORDS giant aneurysm; complex aneurysm; extracranial-intracranial bypass; intracranial-intracranial bypass; pterional craniotomy; orbitozygomatic craniotomy; vascular disorders

$\mathrm{M}$ IDDLE cerebral artery (MCA) aneurysms have long been considered amenable to microsurgical clipping because they are easily accessible through miniaturized craniotomies, can be visualized and manipulated safely after splitting the Sylvian fissure, and have broad necks that can be reconstructed with numerous direct clipping techniques that use intersecting or overlapping clips, "picket-fence" configurations, tandem clipping, or fenestration tubes. ${ }^{7,20,49}$ The MCA aneurysm is the best example of an aneurysm for which results of microsurgery remain superior to those of endovascular therapy; as a consequence, it remains an aneurysm managed preferentially with direct clipping. ${ }^{2,9,42}$ These aneurysms are relatively less amenable to endovascular therapy because coiling is associated with a higher risk of recurrence, retreatment, and rehemorrhage, ${ }^{25,35,36}$ flow diverters often cover len-

ABBREVIATIONS ACA = anterior cerebral artery; $\mathrm{ATA}=$ anterior temporal artery; $\mathrm{CCA}=$ common carotid artery; $\mathrm{EC}=$ extracranial; $\mathrm{ECA}=$ external carotid artery; $\mathrm{IC}=$ intracranial; ICA = internal carotid artery; LSA = lenticulostriate artery; MCA = middle cerebral artery; $m R S=$ modified Rankin Scale; RAG = radial artery graft; $S A H=$ subarachnoid hemorrhage; STA = superficial temporal artery; SVG = saphenous vein graft.

SUBMITTED March 28, 2016. ACCEPTED July 18, 2016.

INCLUDE WHEN CITING Published online November 4, 2016; DOI: 10.3171/2016.7.JNS16772. 
ticulostriate arteries (LSAs) or other arterial trunks, which can cause unintended occlusions and ischemic complications, ${ }^{10,16,40,41,46,47}$ and devices such as intraaneurysmal flow diverters or bifurcation stents are new and unproven and have not been compared rigorously with the microsurgical standard. 5,27

Complex MCA aneurysms can be managed with bypass procedures when conventional clipping fails and a parent artery requires deliberate occlusion. ${ }^{11,31,38,45}$ In a previously published 13 -year experience with 543 patients with an MCA aneurysm, bypass was performed in 21 (4\%) patients, which provided a trapping or proximal occlusion option for some of the more difficult aneurysms in that series. ${ }^{32} \mathrm{~A}$ wide variety of bypass techniques for MCA aneurysms exist because they are so amenable to both traditional extracranial-to-intracranial (EC-IC) bypasses, such as superficial temporal artery (STA) bypass and high-flow interpositional bypass to the cervical carotid artery, and reconstructive IC-IC bypasses, such as the end-to-end reanastomosis and the double-reimplantation technique. $4,6,8,11-14,17-19,22,25,28,30-34,37,39,43,50,51$ The pathological spectrum of MCA aneurysms combined with the variety of applicable bypasses makes it challenging to select the optimal bypass, particularly when these decisions must be made intraoperatively in response to unexpected anatomy or technical complications. To our knowledge, no algorithm to guide these decisions or surgical plans exists. In this report, we review our experience with MCA bypass for complex aneurysms and our patients' results to develop such an algorithm.

\section{Methods \\ Study Design}

This study was approved by the institutional review board of University of California, San Francisco, and performed in compliance with Health Insurance Portability and Accountability Act regulations. The prospective database of the University of California, San Francisco, Vascular Neurosurgery Service was queried for patients who required a bypass for an MCA aneurysm. Medical and operative records, preoperative and postoperative images, angiographic data (including location, size, and type of aneurysm), and the hospital course were reviewed retrospectively.

\section{Definitions and Classifications}

Although an accepted standardized definition does not exist in the literature, previous reports have identified the following features of a "complex" MCA aneurysm: intraluminal thrombus; mycotic or infectious etiology; atherosclerotic thickening of the neck or calcification; giant size ( $\geq 25 \mathrm{~mm}$ in diameter); fusiform or dolichoectatic morphology; serpentine shape; aberrant branch arteries that originate from the sidewall of the aneurysm or at an obtuse angle from the base; and/or involvement of the LSAs. 1,12,23,26,29,39,51 Any one or a combination of these features can prevent conventional clipping and necessitate bypass, and they were recorded specifically for each aneurysm in this study.

The algorithmic approach was based on the location of the MCA aneurysm relative to the point of bifurcation (or trifurcation, quadrifurcation, etc.), and the aneurysms were categorized into 1 of 3 groups: 1) prebifurcation, 2) bifurcation, or 3) postbifurcation aneurysms (Fig. 1).

MCA bypasses were classified as 1 of 7 types., ${ }^{1,37}$ ECIC bypasses involve an EC donor artery, either 1) a scalp artery such as the STA, which creates a low-flow bypass, or 2) the cervical carotid artery (external [ECA], internal [ICA], or common [CCA] carotid artery), which requires an interpositional graft (radial artery graft [RAG] or saphenous vein graft [SVG]) and creates a high-flow bypass. IC-IC bypasses involve an IC donor artery and 1 or more of the following reconstructive anastomoses: 3 ) reanastomosis, in which the aneurysm is excised and 2 transected arterial ends are sutured together end to end; 4) in situ bypass, which uses a side-to-side anastomosis between the efferent artery of the aneurysm and an adjacent parallel donor artery; 5) reimplantation, which uses an end-to-side anastomosis between the transected end of the efferent artery and the side of an adjacent donor artery; 6) interpositional bypass, which joins the donor and recipient arteries with a harvested arterial or venous graft; and 7) combination bypass, which uses any 2 or more of the aforementioned bypass techniques, with 2 or more anastomoses. The double-reimplantation ${ }^{22}$ technique is an example of a combination bypass, as is an ECIC plus IC-IC bypass.

\section{Bypass Indications}

When an aneurysm could not be treated with conventional clip reconstruction, it was treated as follows: 1) trapped, 2) trapped and excised, or 3) partially occluded by proximal or distal occlusion of the parent artery. A bypass procedure was performed whenever a parent artery was deliberately sacrificed to re-perfuse the involved territory and prevent cerebral ischemia or infarction. Although we use preoperative balloon-test occlusion and routinely monitor patients intraoperatively with somatosensory and motor evoked potentials, these tests result in significant falsenegative rates and inconsistencies, and we prefer not to rely on them when deciding on the type of bypass to use. ${ }^{15,17,25,48}$

\section{Results}

\section{Microsurgical Management}

During a 17-year period between January 1998 and March 2015, 30 patients with an MCA aneurysm required a bypass as part of the treatment for their aneurysm. Giant size (16 [53\%] aneurysms), fusiform/dolichoectatic morphology (18 [60\%] aneurysms), and a thrombotic lumen (12 [40\%] aneurysms) were the most common features of these complex MCA aneurysms (Table 1). Fewer than onethird of the patients presented with a ruptured aneurysm. These aneurysms were classified as prebifurcation in 8 patients $(27 \%)$, bifurcation in $5(17 \%)$, and postbifurcation in $17(56 \%)$ (Table 1).

All aneurysms were exposed through pterional (24 [80\%]) or orbitozygomatic-pterional (6 [20\%]) craniotomy and a transsylvian approach. Overall, 10 (33\%) MCA aneurysms were obliterated by trapping, 11 (37\%) by trapping and excision, 8 (27\%) by proximal occlusion, and 1 
Anterior view

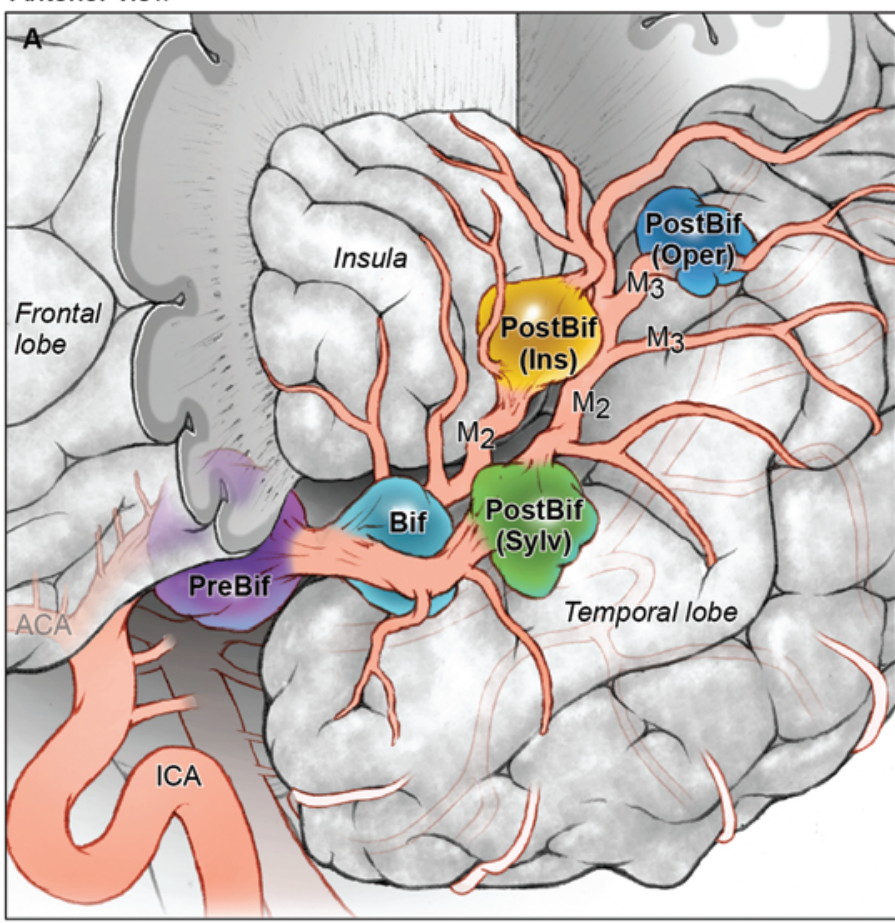

Surgeon's view

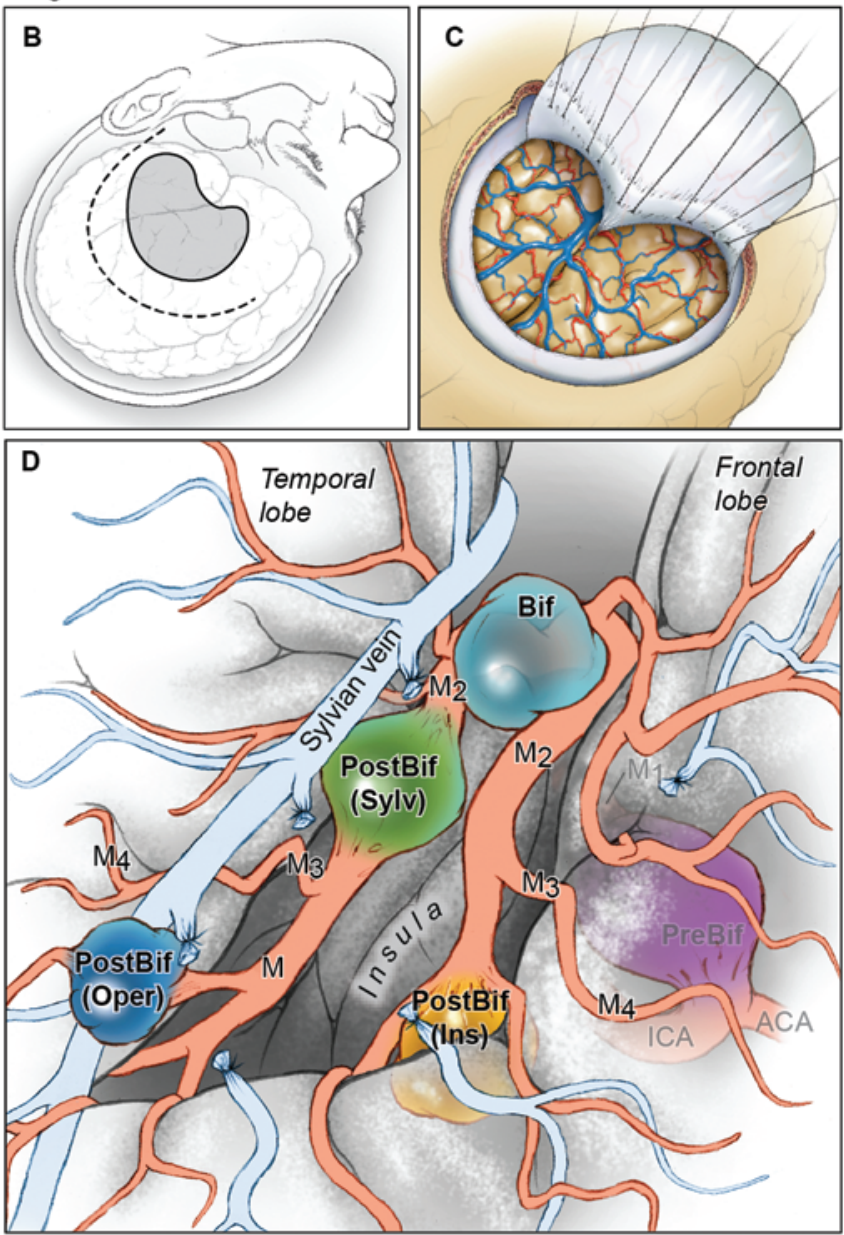

FIG. 1. A: Aneurysms of the MCA were classified according to their location relative to the MCA bifurcation as a prebifurcation (PreBif), bifurcation (Bif), or postbifurcation (PostBif) aneurysm, as seen from an anterior oblique view with the frontal lobe sectioned down to the insula. Postbifurcation aneurysms were located in the Sylvian fissure (Sylv), insular recess (Ins), or operculum (Oper). Bypasses were performed through standard pterional (B and C, surgeon views) or orbitozygomatic craniotomy and wide opening of the Sylvian fissure (D, surgeon view). Copyright Michael Lawton. Published with permission. Figure is available in color online only.

(3\%) by distal occlusion of the parent artery (Table 2). Bifurcation aneurysms had the highest frequency of trapping (80\%), whereas postbifurcation aneurysms had the highest frequency of trapping with excision (47\%).

Bypasses performed in treatment of these 30 aneurysms included 12 (40\%) EC-IC bypasses and 13 (43\%) IC-IC bypasses, and 5 (17\%) combination bypasses, 1 of which was entirely intracranial (Table 3 ). The EC-IC bypasses included 8 STA-MCA bypasses and 4 high-flow interpositional bypasses. The IC-IC bypasses included 6 reanastomoses, 3 reimplantations, $1 \mathrm{M}_{3}-\mathrm{M}_{3}$ segment in situ bypass, and 3 IC interpositional bypasses. The combination bypasses included 2 double reimplantations (ECA-SVG-MCA-MCA and $\mathrm{A}_{1}$-anterior cerebral artery [ACA]-RAG-MCA-MCA), 2 STA-MCA bypasses performed together with separate IC-IC bypasses (1 reanastomosis and 1 anterior temporal artery [ATA]-MCA in situ bypass), and a reanastomosis, reimplantation, and STA-MCA bypass (Table 3 ).

\section{Bypass Strategy According to MCA Aneurysm Classification}

The management of prebifurcation MCA aneurysms was determined by LSA involvement (Fig. 2). These arteries were displaced by aneurysms in 6 of 8 patients (Table 4), and these 6 aneurysms were trapped or excised. Of these aneurysms, 2 were excised and reanastomosed primarily (Fig. 3), and 1 required an interpositional graft. A high-flow EC-IC interpositional grafting was performed in 4 patients. In 1 patient with a mycotic aneurysm, 1 of the bifurcation's trunks was already occluded, and only an STA-MCA bypass was needed. When LSA branches originated from the aneurysm and it could not be trapped, the aneurysm was occluded proximally and bypassed distally with a high-flow EC-IC interpositional graft (2 patients), enabling some retrograde filling of the aneurysm to supply all efferents with a single bypass.

The management of bifurcation MCA aneurysms was determined by their rupture status (Fig. 2). Of 5 patients 
TABLE 1. Clinical and angiographic features of 30 patients with a complex MCA aneurysm

\begin{tabular}{lc}
\hline \multicolumn{1}{c}{ Feature } & Value \\
\hline Mean age in yrs (range) & $47(7-80)$ \\
\hline Sex (no. [\%]) & $13(43)$ \\
\hline Male & $17(57)$ \\
\hline Female & \\
\hline Presentation (no. [\%]) & $8(27)$ \\
\hline SAH & $12(40)$ \\
\hline Focal deficit & $7(23)$ \\
\hline Headache & $2(7)$ \\
\hline Seizure & $1(3)$ \\
\hline Incidental & $7(23)$ \\
\hline Aneurysm feature/morphology (no. [\%]) & $12(40)$ \\
\hline Dolichoectatic & $11(37)$ \\
\hline Thrombotic & $4(13)$ \\
\hline Fusiform & $2(7)$ \\
\hline Mycotic & \\
\hline Serpentine & $16(53)$ \\
\hline Aneurysm size (no. [\%]) & $9(23)$ \\
\hline Giant $(\geq 25 \mathrm{~mm})$ & $5(27)$ \\
\hline Large $(10-24 \mathrm{~mm})$ &
\end{tabular}

TABLE 2. Aneurysm obliteration techniques used in 30 patients

\begin{tabular}{lccccc}
\hline $\begin{array}{c}\text { Aneurysm } \\
\text { Location }\end{array}$ & Trapping & Excision & $\begin{array}{c}\text { Proximal } \\
\text { Occlusion }\end{array}$ & $\begin{array}{c}\text { Distal } \\
\text { Occlusion }\end{array}$ & Total \\
\hline Prebifurcation & 3 & 3 & 2 & 0 & 8 \\
\hline Bifurcation & 4 & 0 & 0 & 1 & 5 \\
\hline Postbifurcation & 3 & 8 & 6 & 0 & 17 \\
\hline Total & 10 & 11 & 8 & 1 & 30 \\
\hline
\end{tabular}

with a bifurcation aneurysm, 4 presented with subarachnoid hemorrhage (SAH), necessitating complete aneurysm exclusion (Table 5). Conventional clipping was not possible because of recurrence after coiling in 2 patients, mycotic aneurysm in 2 patients, and giant calcified thrombotic aneurysm in 1 patient. In 3 patients, the bifurcations were reconstructed with a combination bypass (a double reimplantation with an EC donor, a double reimplantation with an IC donor, and an ATA-MCA plus an STA-MCA bypass). Two other patients with a mycotic aneurysm had only 1 viable trunk, and their aneurysms were managed with trapping and revascularization with MCA-ATA reimplantation or an STA-MCA bypass. Figure 4 shows an example of a double-reimplantation technique used for a complex MCA bifurcation aneurysm.

The management of postbifurcation MCA aneurysms was determined by their location in the candelabra (Fig. 2). Postbifurcation MCA aneurysms were treated with all of the bypass types except the EC-IC interpositional bypass, because the flow requirements of a distal efferent artery do not call for high flow (Table 6). The most common bypasses were the STA-MCA bypass and primary reanastomosis. The STA-MCA bypass to a cortical $\mathbf{M}_{4}$ recipient was ideal for a postbifurcation MCA aneurysm located on the remote insular segments in the distal Sylvian fissure. The flash fluorescence technique identified the efferent artery on the cortical surface, and the superficial STA-MCA bypass was followed by proximal aneurysm occlusion (5 patients) or trapping (1 patient). Simple distal aneurysms with a single afferent and efferent artery were reanastomosed primarily, without needing another donor artery or harvesting a scalp artery (4 patients). Reanastomoses were performed in the Sylvian fissure (early $\mathrm{M}_{2}$ insular segment), where a wide Sylvian fissure split created working space, or distally in the operculum $\left(\mathrm{M}_{3}\right.$ segment), where the field was superficial and shallow. Other IC-IC options required an adjacent donor artery. Reimplantation and interpositional bypass were each performed in 2 patients, and in situ bypass was performed in 1 patient (Fig. 5). Two postbifurcation MCA aneurysms were observed at significant branch points with 2 efferent arteries requiring a combination bypass (reanastomosis-reimplantation plus STA-MCA bypass in 1 patient and reanastomosis plus STA-MCA bypass in another patient).

\section{Surgical Results}

Overall, 29 of 30 treated MCA aneurysms were occluded completely, as confirmed angiographically. In 1 case (Case 8), a small residual aneurysm segment was left deliberately for postoperative coiling. Twenty-seven bypasses were patent according to postoperative angiography. Of the 3 patients with an occluded bypass, 2 had postoperative neurological deficits, and 1 did not have complications related to the occlusion. Two of the 3 bypass occlusions occurred with a prebifurcation MCA aneurysm, and 2 of the 3 occlusions occurred with the excision-reanastomosis

TABLE 3. Bypass techniques used in 30 patients with a complex MCA aneurysm

\begin{tabular}{|c|c|c|c|c|c|c|c|c|}
\hline \multirow{2}{*}{$\begin{array}{l}\text { Aneurysm } \\
\text { Location }\end{array}$} & \multicolumn{2}{|c|}{ EC-IC Bypass } & \multicolumn{4}{|c|}{ IC-IC Bypass } & \multirow{2}{*}{$\begin{array}{c}\text { Combination } \\
\text { Bypass }\end{array}$} & \multirow[b]{2}{*}{ Total } \\
\hline & Low Flow & High Flow & Reanastomosis & Reimplantation & In Situ Bypass & Interposition & & \\
\hline Prebifurcation & 1 & 4 & 2 & 0 & 0 & 1 & 0 & $8(27)$ \\
\hline Bifurcation & 1 & 0 & 0 & 1 & 0 & 0 & 3 & $5(17)$ \\
\hline Postbifurcation & 6 & 0 & 4 & 2 & 1 & 2 & 2 & $17(56)$ \\
\hline Total & $8(27)$ & $4(13)$ & $6(20)$ & $3(10)$ & $1(3)$ & $3(10)$ & $5(17)$ & 30 \\
\hline
\end{tabular}

Values are expressed as number (percent). 


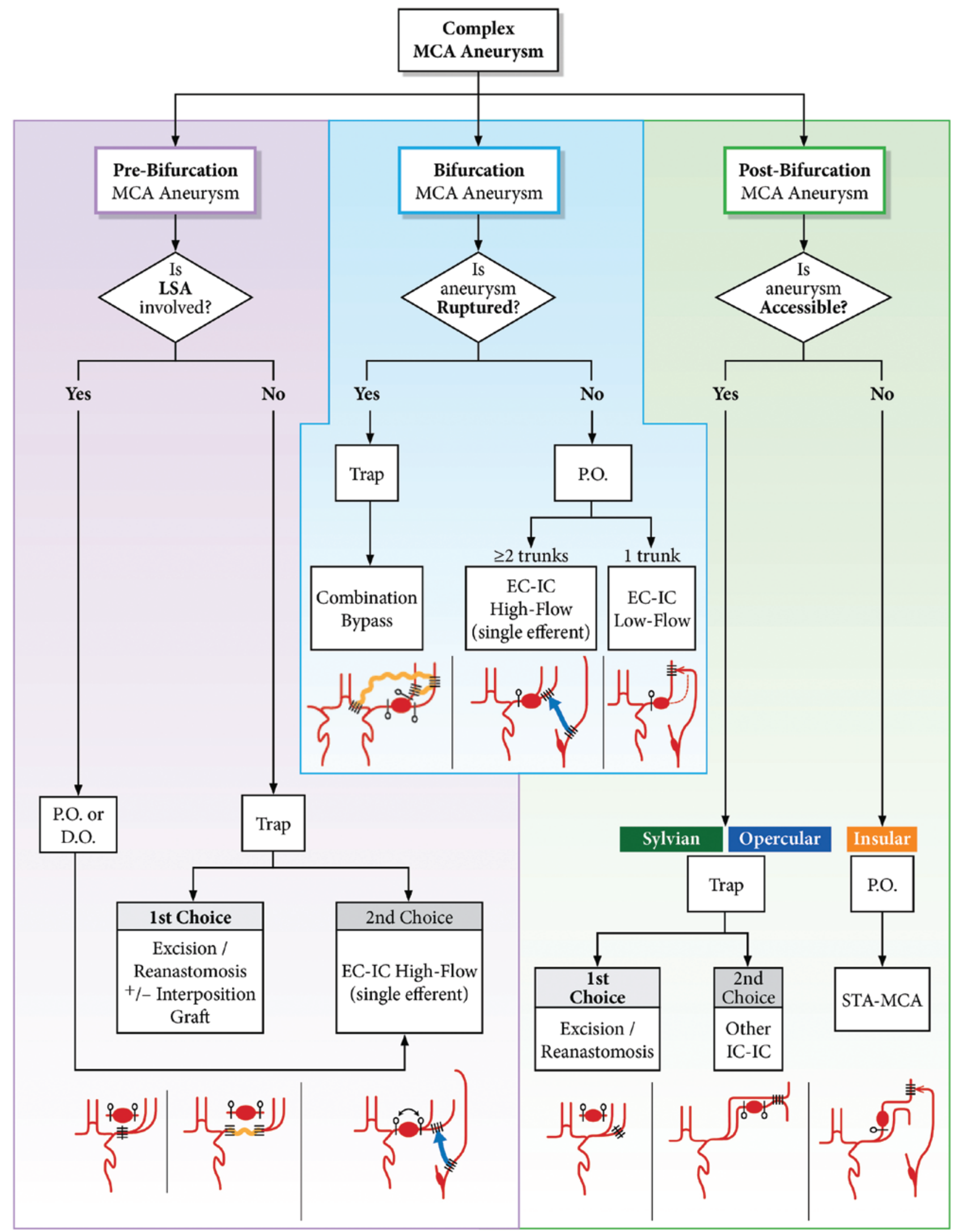

FIG. 2. Algorithm for treatment and bypass strategy for complex MCA aneurysms. D.O. = distal occlusion; P.O. = proximal occlusion. Figure is available in color online only. 
TABLE 4. Clinical, angiographic, and surgical characteristics of 8 patients with a prebifurcation MCA aneurysm

\begin{tabular}{|c|c|c|c|c|c|c|c|c|c|c|}
\hline $\begin{array}{l}\text { Case } \\
\text { No. }\end{array}$ & $\begin{array}{l}\text { Age } \\
\text { (yrs), } \\
\text { Sex }\end{array}$ & Presentation & $\begin{array}{c}\text { Aneurysm } \\
\text { Location/Segment } \\
\text { \& Size }(\mathrm{mm})\end{array}$ & $\begin{array}{l}\text { Complex } \\
\text { Aneurysm } \\
\text { Feature(s) }\end{array}$ & $\begin{array}{l}\text { Aneurysm } \\
\text { Treatment }\end{array}$ & $\begin{array}{c}\text { Bypass } \\
\text { Performed }\end{array}$ & $\begin{array}{l}\text { Preop } \\
\text { mRs } \\
\text { Score }\end{array}$ & $\begin{array}{l}\text { Late } \\
\text { mRS } \\
\text { Score }\end{array}$ & $\begin{array}{l}\text { Aneurysm } \\
\text { Occlusion }\end{array}$ & $\begin{array}{l}\text { Bypass } \\
\text { Patency }\end{array}$ \\
\hline 1 & $27, \mathrm{~F}$ & $\begin{array}{l}\mathrm{HA} \text {, recurrence after } \\
\text { clipping }\end{array}$ & Lt $\mathrm{M}_{1}, 42$ & $G, D$ & $\mathrm{Tr}$ & ECA-RAG-M ${ }_{2}$ & 4 & 4 & Complete & Patent \\
\hline 2 & $58, F$ & $\begin{array}{l}\text { Enlarging aneurysm, } \\
\text { progressive dyspha- } \\
\text { sia, It hemiparesis }\end{array}$ & Rt $M_{1}, 53$ & $G, D, T$ & $\mathrm{Tr}$ & ECA-SVG-M ${ }_{2}$ & 2 & 1 & Complete & Patent \\
\hline 3 & $12, \mathrm{M}$ & $\mathrm{SAH}$ & Lt $\mathrm{M}_{1}, 32$ & G, Fu, Myc & $\mathrm{Tr}$ & STA-M ${ }_{2}$ & 1 & 0 & Complete & Patent \\
\hline 4 & $63, F$ & $\mathrm{HA}$ & Rt $M_{1}, 18$ & $\mathrm{~T}$ & Ex & $\mathrm{M}_{1}-\mathrm{M}_{1}$ reanastomosis & 0 & 3 & Complete & Occluded \\
\hline 5 & $66, F$ & Szs & Lt $\mathrm{M}_{1}, 26$ & G, D & $\mathrm{PO}$ & ECA-SVG-M 2 & 1 & 3 & Complete & Occluded \\
\hline 6 & $7, \mathrm{M}$ & $\mathrm{SAH}$ & Rt $M_{1}, 29$ & G, D & Ex & $\mathrm{M}_{1}-\mathrm{RAG}-\mathrm{M}_{1}$ & 5 & 3 & Complete & Patent \\
\hline 7 & $73, M$ & Difficulty finding words & Lt M 1,46 & $\mathrm{G}, \mathrm{S}, \mathrm{T}$ & Ex & $\mathrm{M}_{1}-\mathrm{M}_{1}$ reanastomosis & 1 & 1 & Complete & Patent \\
\hline 8 & 47, M & Lt hemiparesis & Rt $M_{1}, 27$ & G, D & PO & CCA-SVG-M ${ }_{2}$ & 3 & 5 & Residual & Patent \\
\hline
\end{tabular}

$\mathrm{D}=$ dolichoectatic; $\mathrm{Ex}=$ excision; $\mathrm{Fu}=$ fusiform; $\mathrm{G}=$ giant $(\geq 25 \mathrm{~mm}) ; \mathrm{HA}=$ headache; Myc = mycotic; $\mathrm{PO}=$ proximal occlusion; $\mathrm{S}=$ serpentine; $\mathrm{Szs}=\mathrm{seizures} ; \mathrm{T}=$ thrombotic; $\mathrm{Tr}=$ trapping.

technique. In 1 of these cases, the $\mathrm{M}_{1}$ segment thrombosed after clipping the aneurysm, and the bypass was performed in part to reopen the parent artery, which suggests an underlying hypercoagulable state.

No deaths that resulted from surgery were found. Figure 6 summarizes preoperative and postoperative modi- fied Rankin Scale (mRS) scores. The median postoperative mRS score was 1 (range $0-5$ ). The conditions of 27 patients (90\%) either improved or were unchanged neurologically. Good outcomes (mRS score $\leq 2)$ were observed in 24 patients $(80 \%)$ at the last follow-up (mean duration 2.37 years). Poor neurological outcomes were caused by
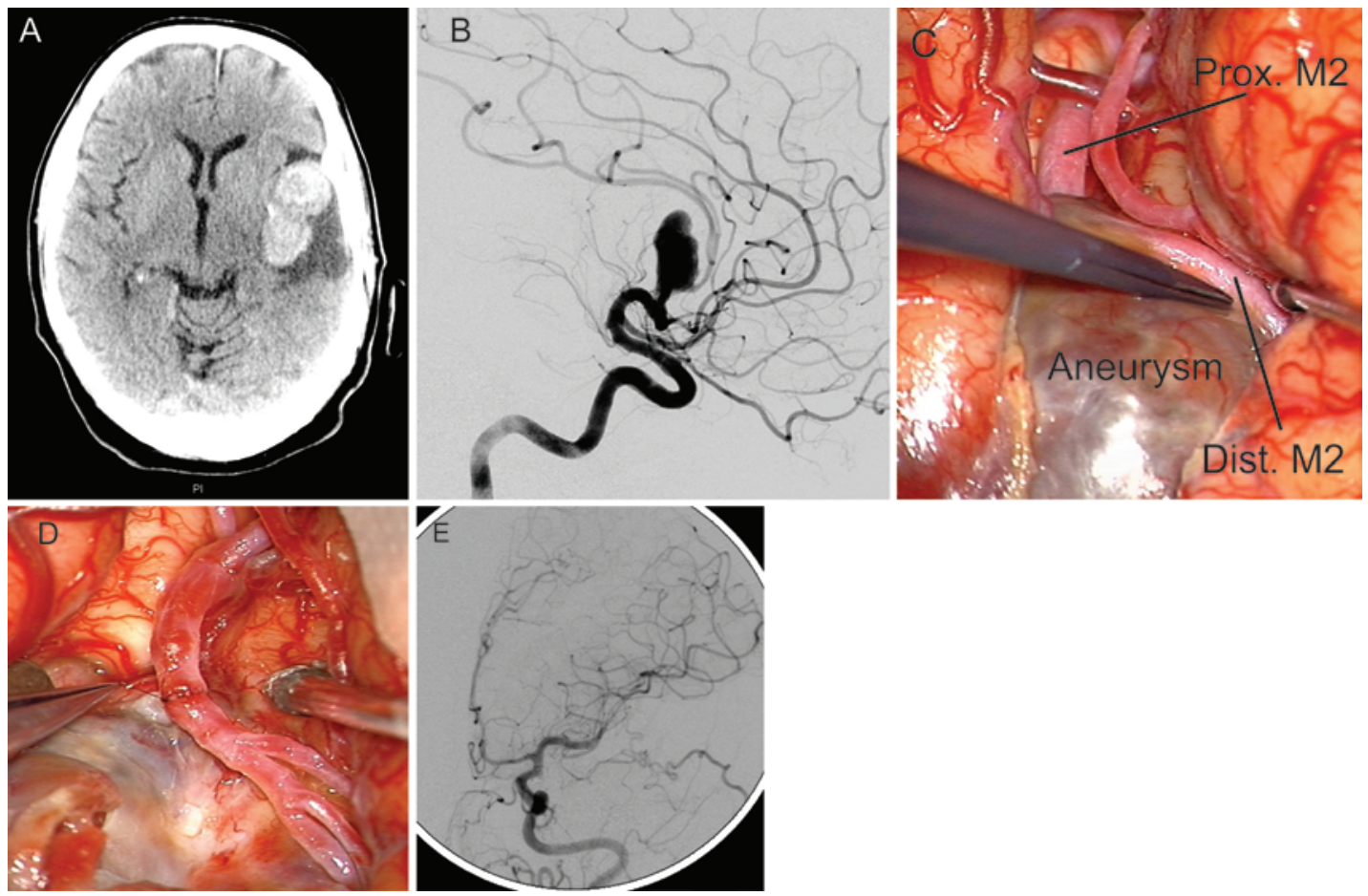

FIG. 3. Case 7. Prebifurcation MCA aneurysm. A: Axial CT image of a 73-year-old man who presented with difficulty finding words and was found to have a giant thrombotic left MCA aneurysm. B: Digital subtraction angiography (DSA) image (left ICA injection, lateral view) revealed a small luminal component arising from the $\mathrm{M}_{1}$ segment proximal to the MCA bifurcation. C: After splitting the Sylvian fissure, the greenish-colored thrombotic aneurysm was found to separate the proximal and distal $M_{1}$ segments. D: The reconstructed $\mathrm{M}_{1}$ segment was located proximal to the MCA bifurcation. E: Postoperative angiograpm (left ICA injection, lateral view) revealed complete elimination of the aneurysm and excellent MCA revascularization. Dist. = distal; Prox. = proximal. Figure is available in color online only. 
TABLE 5. Clinical, angiographic, and surgical characteristics of 5 patients with a bifurcation MCA aneurysm

\begin{tabular}{|c|c|c|c|c|c|c|c|c|c|c|}
\hline $\begin{array}{l}\text { Case } \\
\text { No. }\end{array}$ & $\begin{array}{l}\text { Age } \\
\text { (yrs), } \\
\text { Sex }\end{array}$ & Presentation & $\begin{array}{c}\text { Aneurysm } \\
\text { Location \& Size } \\
(\mathrm{mm})\end{array}$ & $\begin{array}{l}\text { Complex } \\
\text { Aneurysm } \\
\text { Feature(s) }\end{array}$ & $\begin{array}{l}\text { Aneurysm } \\
\text { Treatment }\end{array}$ & $\begin{array}{l}\text { Bypass } \\
\text { Performed }\end{array}$ & $\begin{array}{l}\text { Preop } \\
\text { mRS } \\
\text { Score }\end{array}$ & $\begin{array}{l}\text { Late } \\
\text { mRS } \\
\text { Score }\end{array}$ & $\begin{array}{l}\text { Aneurysm } \\
\text { Occlusion }\end{array}$ & $\begin{array}{l}\text { Bypass } \\
\text { Patency }\end{array}$ \\
\hline 9 & $74, \mathrm{~F}$ & $\mathrm{SAH}$ & Lt $M_{1}-M_{2}, 26$ & $\mathrm{G}, \mathrm{T}$ & $\operatorname{Tr}$ & $\begin{array}{l}\text { ECA-SVG-M } \mathrm{M}_{2}+\mathrm{M}_{2} \text { (double } \\
\text { reimplantation) }\end{array}$ & 1 & 1 & Complete & Patent \\
\hline 10 & $17, \mathrm{~F}$ & SAH, It hemiparesis & Rt $M_{1}-M_{2}, 9$ & Myc & $\mathrm{Tr}$ & STA-M ${ }_{2}$ & 4 & 0 & Complete & Patent \\
\hline 11 & $24, \mathrm{M}$ & SAH, It hemiparesis & Rt $M_{1}-M_{2}, 10$ & Myc & $\operatorname{Tr}$ & ATA-M $\mathrm{M}_{2}$ reimplantation & 4 & 3 & Complete & Patent \\
\hline 12 & $20, \mathrm{~F}$ & $\mathrm{HA}, \mathrm{Rec}$ & Lt $\mathrm{M}_{1}-\mathrm{M}_{2}, 26$ & G, Rec & DO & ATA-M $M_{2}+$ STA-M & 1 & 1 & Complete & Patent \\
\hline 13 & $48, F$ & $\mathrm{SAH}, \mathrm{Rec}$ & Rt $M_{1}-M_{2}, 4$ & $\operatorname{Rec}$ & $\operatorname{Tr}$ & $\begin{array}{l}\text { A1-RAG- } \mathrm{M}_{2}+\mathrm{M}_{2} \text { (double } \\
\text { reimplantation) }\end{array}$ & 0 & 0 & Complete & Patent \\
\hline
\end{tabular}

$\mathrm{DO}=$ distal occlusion; $\mathrm{Rec}=$ recurrence after coiling.

bypass occlusion in 2 patients (Cases 4 and 5) with a prebifurcation aneurysm (Table 4). Also, a patient with a giant dolichoectatic prebifurcation aneurysm that also involved the carotid terminus and supraclinoid carotid artery and MCAs and extended from the origin of the ophthalmic aneurysms to the MCA bifurcation suffered a postoperative epidural hematoma and impending herniation. The bleeding source was the STA, and the bypass was patent (Table 4) (Case 8). No other postoperative complication was found.

\section{Discussion}

The anterior and posterior cerebral arteries have communicating arteries that contribute collateral blood flow from left to right via the anterior communicating artery and from anterior to posterior via the posterior communicating artery. Communicating arteries protect distal territories from ischemic complications after natural or iatrogenic occlusions and decrease the need for microsurgical bypass after deliberate arterial sacrifice during complex aneurysm treatment. In contrast, the MCA lacks a communicating artery, is vulnerable to ischemic complications after therapeutic occlusions, and depends on microsurgical bypass with unclippable aneurysms. For example, the number of patients who underwent MCA bypass reported here is 3 times larger than the number of patients who underwent ACA bypass reported previously from our institution (10 patients). ${ }^{1}$ Moreover, of the 3 main cerebral arteries, the MCA supplies the largest and most eloquent territories in the cerebral hemispheres. Therefore, complex MCA aneurysms not amenable to direct clipping require a reconstructive posture toward bypass that restores blood flow robustly to avoid neurological complications.

This experience with bypass surgery for 30 complex MCA aneurysms derives from a larger cohort of 1426 MCA aneurysms in 872 patients treated microsurgically over a 17 -year period. Only $2.1 \%$ of the MCA aneurysms or $3.4 \%$ of the patients with an MCA aneurysm required an MCA bypass. Although the frequency of bypass seems low, it indicates that revascularization remains an essential part of the microsurgical armamentarium. This experience also shows the gamut of bypasses that are available for MCA aneurysms; 18 different bypasses were used in these 30 patients because of variations in reconstructive technique, combination of bypasses, EC donor site, type of interpositional graft, or recipient site. Therefore, the spectrum of bypass options can be overwhelming and confusing. Our approach over this period was to individualize the bypass strategy for each patient based on pathology, afferent and efferent artery anatomy, and flow requirements. However, retrospective review of one of the largest MCA bypass experiences enabled us to distill our practices and formulate an overall strategy based on our classification of prebifurcation, bifurcation, and postbifurcation MCA aneurysms. An algorithmic approach is needed to guide MCA bypass planning and intraoperative decision-making (Figs. 2 and 7).

\section{Prebifurcation MCA Aneurysms}

The strategy for treating prebifurcation MCA aneurysms is dictated by the presence or absence of LSAs along the aneurysmal segment that supply vital basal ganglial structures (Fig. 2). ${ }^{3,18,24,39,45,51}$ It is fortunate that the majority $(75 \%)$ of complex prebifurcation aneurysms displaced these perforators proximally or distally as they enlarged to a giant size or morphed into dolichoectatic lesions. Absence of LSAs along the aneurysmal segment enabled aneurysm trapping, which then creates an opportunity to excise the aneurysm and reconstruct the $M_{1}$ segment with primary reanastomosis, if the pathological segment is short (Fig. 8). ${ }^{50}$ Primary reanastomosis requires a single end-to-end anastomosis and is therefore quick, but it also requires some tortuosity or redundancy of the parent artery and extensive dissection to mobilize the afferent and efferent arteries and bring the transected ends together without tension. Careful anatomical assessment and a high likelihood of success are needed before committing to primary reanastomosis, because failure requires either an interpositional graft or a change in strategy to an ECIC high-flow bypass, which are both executed best before aneurysm trapping. Primary reanastomosis fails when a long segment of aneurysm is excised, pathological arterial wall remains at the transected ends, and/or the ends are approximated under tension with suture pullout or breakage. Complete aneurysm excision and the problem of an unbridgeable arterial gap are directly related; thorough excision increases the gap and failure rate of reanastomosis, whereas incomplete aneurysm excision decreases the gap 

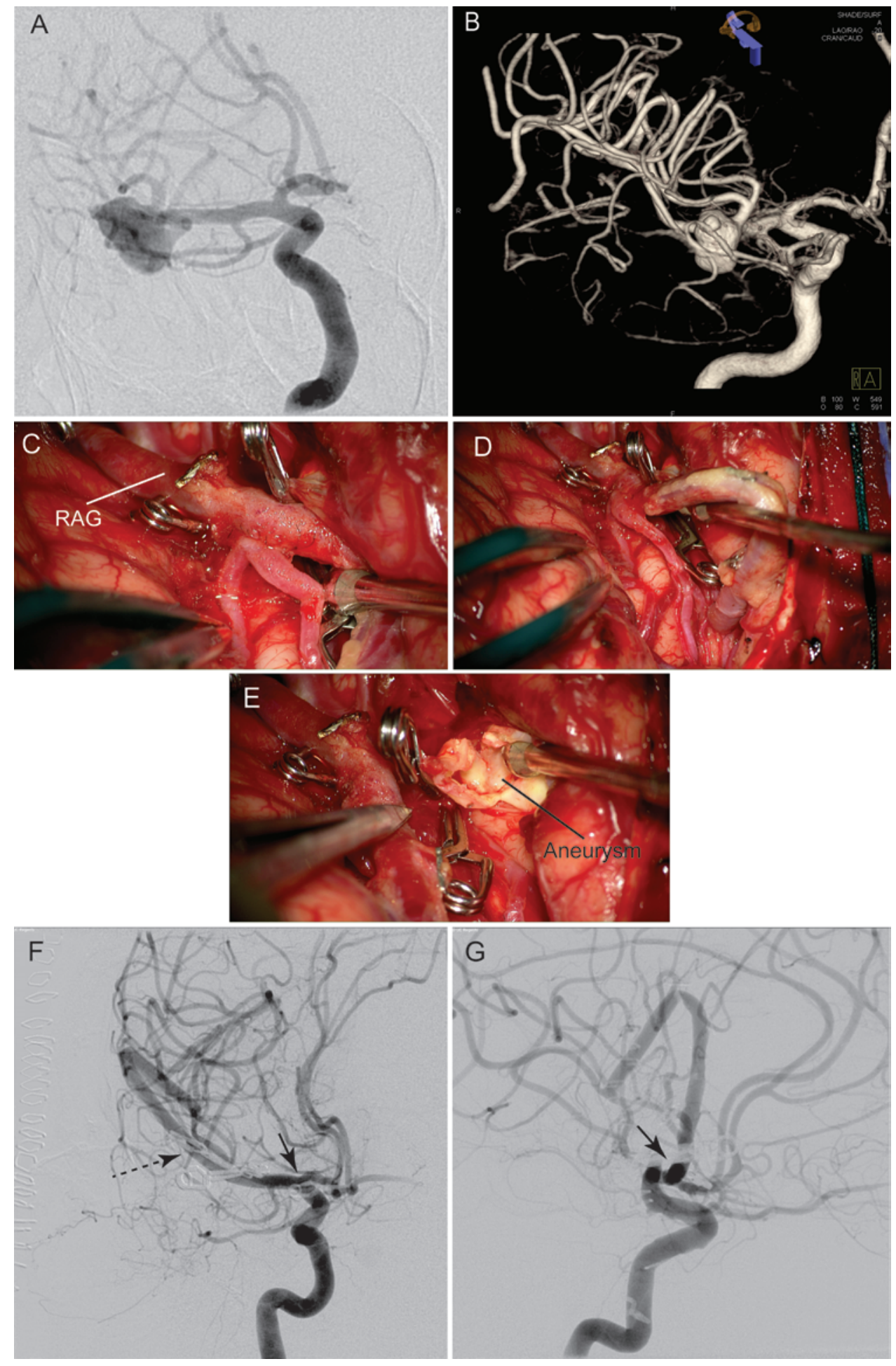

FIG. 4. Bifurcation MCA aneurysm. A 71-year-old woman presented with an SAH and was found to have a large calcified right MCA bifurcation aneurysm. A: DSA image (right ICA injection, anterior oblique view) revealed the inferior trunk originating from the base of the aneurysm and recurring along the course of the parent $\mathrm{M}_{1}$ segment. $\mathrm{B}$ : $3 \mathrm{D}$ rotational angiogram revealing the superior trunk, also originating from the base of the aneurysm and coursing superiorly. The aneurysm was bypassed with a double-reimplantation technique to reimplant the superior trunk onto the graft with an end-to-side anastomosis (C) and connect the distal end of the graft to the inferior trunk with another end-to-side anastomosis (D). E: This atherosclerotic unclippable aneurysm was then trapped completely and deflated. Postoperative angiograms (right ICA injection, anteroposterior [F] and lateral [G] views) revealing complete elimination of the aneurysm, a patent bypass graft, and excellent MCA revascularization. Solid arrows point to the proximal anastomosis to the $\mathrm{A}_{1}$ segment, and the dashed arrow points to the anastomosis with the superior $\mathrm{M}_{2}$ trunk. Figure is available in color online only. 
TABLE 6. Clinical, angiographic, and surgical characteristics of 17 patients with a postbifurcation MCA aneurysm

\begin{tabular}{|c|c|c|c|c|c|c|c|c|c|c|}
\hline $\begin{array}{l}\text { Case } \\
\text { No. }\end{array}$ & $\begin{array}{c}\text { Age } \\
\text { (yrs), } \\
\text { Sex }\end{array}$ & Presentation & $\begin{array}{l}\text { Aneurysm } \\
\text { Location \& } \\
\text { Size }(\mathrm{mm})\end{array}$ & $\begin{array}{l}\text { Complex } \\
\text { Aneurysm } \\
\text { Feature(s) }\end{array}$ & $\begin{array}{l}\text { Aneurysm } \\
\text { Treatment }\end{array}$ & $\begin{array}{l}\text { Bypass } \\
\text { Performed }\end{array}$ & $\begin{array}{l}\text { Preop } \\
\text { mRs } \\
\text { Score }\end{array}$ & $\begin{array}{l}\text { Late } \\
\text { mRS } \\
\text { Score }\end{array}$ & $\begin{array}{l}\text { Aneurysm } \\
\text { Occlusion }\end{array}$ & $\begin{array}{l}\text { Bypass } \\
\text { Patency }\end{array}$ \\
\hline 14 & $80, \mathrm{~F}$ & $\mathrm{HA}$ & Rt M, 13 & $\mathrm{Fu}$ & Ex & $\mathrm{M}_{3}-\mathrm{M}_{3}$ reanastomosis & 1 & 0 & Complete & Occluded \\
\hline 15 & $19, M$ & $\mathrm{HA}$ & $\mathrm{Rt} \mathrm{M}_{3}, 15$ & $\mathrm{D}, \mathrm{T}$ & Ex & $\mathrm{M}_{3}-\mathrm{M}_{3}$ reanastomosis & 1 & 1 & Complete & Patent \\
\hline 16 & $40, M$ & TIA, Szs & Rt M, 8 & $\mathrm{Fu}, \mathrm{T}$ & Ex & $\mathrm{M}_{2}-\mathrm{M}_{2}$ reimplantation & 1 & 1 & Complete & Patent \\
\hline 17 & $66, M$ & TIA (It facial droop) & $\mathrm{Rt} \mathrm{M}_{3}, 9$ & $\mathrm{~T}$ & Ex & $\mathrm{M}_{2}-\mathrm{M}_{2}$ reanastomosis & 1 & 0 & Complete & Patent \\
\hline 18 & $32, \mathrm{M}$ & $\mathrm{SAH}$ & Lt $\mathrm{M}_{2}, 14$ & $\mathrm{Fu}$ & PO & STA-M 4 & 1 & 0 & Complete & Patent \\
\hline 19 & $64, \mathrm{~F}$ & TIA (It hemiparesis) & Rt M, 12 & $\mathrm{Fu}, \mathrm{T}$ & PO & STA-M 4 & 1 & 0 & Complete & Patent \\
\hline 20 & $59, \mathrm{~F}$ & Dysarthria & $\mathrm{Lt} \mathrm{M}_{2}, 8$ & $\mathrm{Fu}$ & PO & STA-M 4 & 1 & 1 & Complete & Patent \\
\hline 21 & $61, M$ & Lt sensory deficit & $\mathrm{Rt} \mathrm{M}_{2}, 53$ & $G, S$ & $\operatorname{Tr}$ & STA-M 4 & 1 & 0 & Complete & Patent \\
\hline 22 & $42, \mathrm{~F}$ & $\mathrm{HA}$ & Lt $\mathrm{M}_{2}, 31$ & $\mathrm{G}, \mathrm{T}$ & PO & STA-M 4 & 1 & 0 & Complete & Patent \\
\hline 23 & $74, \mathrm{M}$ & $\begin{array}{l}\text { Progressive dysphasia, } \\
\text { drop attack }\end{array}$ & Rt $M_{3}, 10$ & $\mathrm{Fu}$ & PO & STA-M ${ }_{4}$ & 1 & 1 & Complete & Patent \\
\hline 24 & $39, \mathrm{~F}$ & $\mathrm{SAH}$ & $\mathrm{Lt} \mathrm{M}_{3}, 26$ & G, Fu, Myc & Ex & $\mathrm{M}_{3}-\mathrm{M}_{3}$ reanastomosis & 1 & 0 & Complete & Patent \\
\hline 25 & $36, M$ & Szs & Rt M, 26 & $\mathrm{G}, \mathrm{D}, \mathrm{T}$ & Ex & $\mathrm{M}_{2}-\mathrm{STA}-\mathrm{M}_{2}$ interposition & 1 & 0 & Complete & Patent \\
\hline 26 & $57, \mathrm{~F}$ & TIA (It hemiparesis) & Rt M 2,11 & $\mathrm{Fu}, \mathrm{T}$ & PO & $\mathrm{M}_{3}-\mathrm{M}_{3}$ in situ bypass & 3 & 0 & Complete & Patent \\
\hline 27 & $68, \mathrm{~F}$ & $\mathrm{HA}$ & Rt $M_{2}, 27$ & $\mathrm{G}, \mathrm{T}$ & Ex & $\begin{array}{l}\text { STA- } \mathrm{M}_{4}, \mathrm{M}_{2}-\mathrm{M}_{2} \text { reanastomo- } \\
\text { sis, } \mathrm{M}_{2}-\mathrm{M}_{2} \text { reimplantation }\end{array}$ & 1 & 1 & Complete & Patent \\
\hline 28 & $23, \mathrm{~F}$ & Rt hemiparesis \& aphasia & Lt $M_{2}, 38$ & $\mathrm{G}, \mathrm{Fu}$ & $\operatorname{Tr}$ & $\mathrm{M}_{2}-\mathrm{M}_{2}$ reimplantation & 4 & 1 & Complete & Patent \\
\hline 29 & $15, M$ & $\begin{array}{l}\text { Recurrence after clipping, } \\
\text { TIA (It hemiparesis) }\end{array}$ & $\mathrm{Rt} \mathrm{M}, 26$ & $G$ & $\mathrm{Tr}$ & $\mathrm{M}_{2}-\mathrm{RAG}-\mathrm{M}_{2}$ interposition & 1 & 1 & Complete & Patent \\
\hline 30 & $37, \mathrm{~F}$ & Incidental & Rt M, 10 & $\mathrm{Fu}$ & Ex & $\begin{array}{l}\mathrm{M}_{2}-\mathrm{M}_{2} \text { reanastomosis, } \\
\text { STA- } \mathrm{M}_{2}\end{array}$ & 0 & 0 & Complete & Patent \\
\hline
\end{tabular}

$\mathrm{TIA}=$ transient ischemic attack.

but might incorporate pathological tissues into the reanastomosis and occlude it.

With interpositional grafting, a graft must be harvested in advance and be ready to suture. The caliber of the RAG is well matched to the $\mathrm{M}_{1}$ segment. Two end-to-end anastomoses are usually performed with short suture lines that are quicker than end-to-side anastomoses. However, the MCA territory cannot be reperfused until both anastomoses are completed. If reperfusion is needed between anastomoses, or if an LSA originates at one of the transected ends, an end-to-side anastomosis can be performed first, followed by reperfusion and an end-to-end anastomosis. With EC-IC high-flow bypass instead of an interpositional graft, the bypass is performed first, before trapping and excising the aneurysm. Like the IC-IC interpositional graft, this EC-IC interpositional bypass also requires 2 anastomoses, one to an efferent trunk and the other to the cervical ECA or CCA. The same EC-IC interpositional bypass is used when the prebifurcation MCA aneurysm involves the LSAs and the aneurysm cannot be trapped. Proximal occlusion is performed instead, and the bypass supplies anterograde flow to the recipient trunk, retrograde flow to the other trunks, and retrograde flow through the aneurysm to the LSAs. A single high-flow bypass is needed for prebifurcation aneurysms because a competent bifurcation allows 1 bypass to retrogradely fill the unbypassed efferent trunks. Exceptions to this algorithm occurred when a major trunk was already occluded with preexisting ischemic injury and the reduced revascularization requirements of a single trunk were met with a single low-flow STA-MCA bypass.

\section{Bifurcation MCA Aneurysms}

The management of bifurcation MCA aneurysms is determined by the rupture status of the patient (Fig. 2). Bifurcation aneurysms in patients who present with SAH must be excluded completely, and when conventional clipping fails, the aneurysm is trapped and multiple trunks are revascularized. Combination bypasses use 2 or more bypasses to rebuild the bifurcation; examples include the double-reimplantation bypass (Fig. 9), EC-IC plus IC-IC bypasses, 2 IC-IC bypasses, and 2 EC-IC bypasses. The double-reimplantation technique ${ }^{22}$ is an ideal bypass because it delivers high flow through an RAG, and using the $\mathrm{A}_{1}$ segment as an IC donor shortens the length of the graft and keeps it entirely intracranial. This bypass requires 3 end-to-side anastomoses, typically 2 at each end of the graft and 1 midgraft reimplantation. The successive reimplantation technique can be extended to reconstruct trifurcations with triple reimplantations or quadrifurcations with quadruple reimplantations. Other combination bypasses can be completed with 2 anastomoses when the EC-IC bypass is an STA-MCA bypass and the IC-IC bypass is either a reimplantation, reanastomosis, or an in situ bypass. EC-IC or IC-IC interpositional bypasses require 3 anastomoses.

Unruptured bifurcation MCA aneurysms can be managed with proximal occlusion, rather than trapping, and distal high-flow EC-IC bypass to a single efferent trunk, 

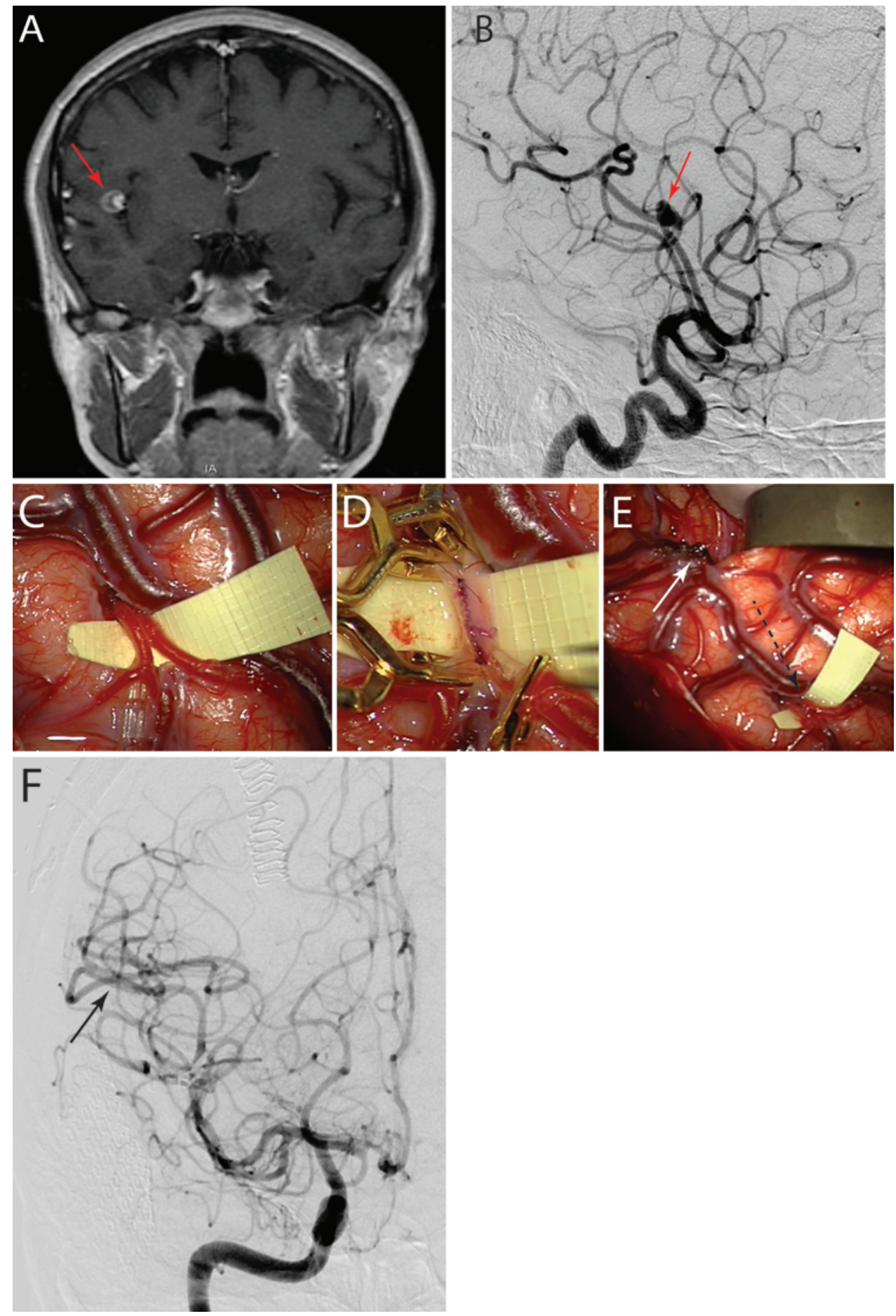

FIG. 5. Case 26. Postbifurcation MCA aneurysm. A: Coronal T1-weighted Gd-enhanced MR image obtained in a 57-year-old woman who presented with an episode of left hemiparesis and was found to have a distal thrombotic right MCA aneurysm diagnosed with MRI. B: DSA image (right ICA injection, lateral view) revealing the aneurysm on the insular $\mathrm{M}_{2}$ segment (red arrows). The aneurysm was proximally occluded and bypassed distally with an in situ $\mathrm{M}_{3}-\mathrm{M}_{3}$ bypass. C: The flash fluorescence technique identified the posterior parietal artery as the efferent artery and the angular artery as an uninvolved adjacent artery. D: These 2 cortical arteries were joined with a side-to-side anastomosis, and the angular artery served as an in situ donor artery. E: Overview of the surgical field, showing that the flash fluorescence technique spares the additional dissection needed to trace the efferent arteries from the aneurysm to the cortical surface to determine the recipient site of the bypass (white arrow, permanent clip; dashed black arrow, in situ anastomosis). F: Postoperative angiogram (right ICA injection, anteroposterior view) demonstrating complete elimination of the aneurysm, a patent anastomosis (solid black arrow), and excellent MCA revascularization. Figure is available in color online only. 


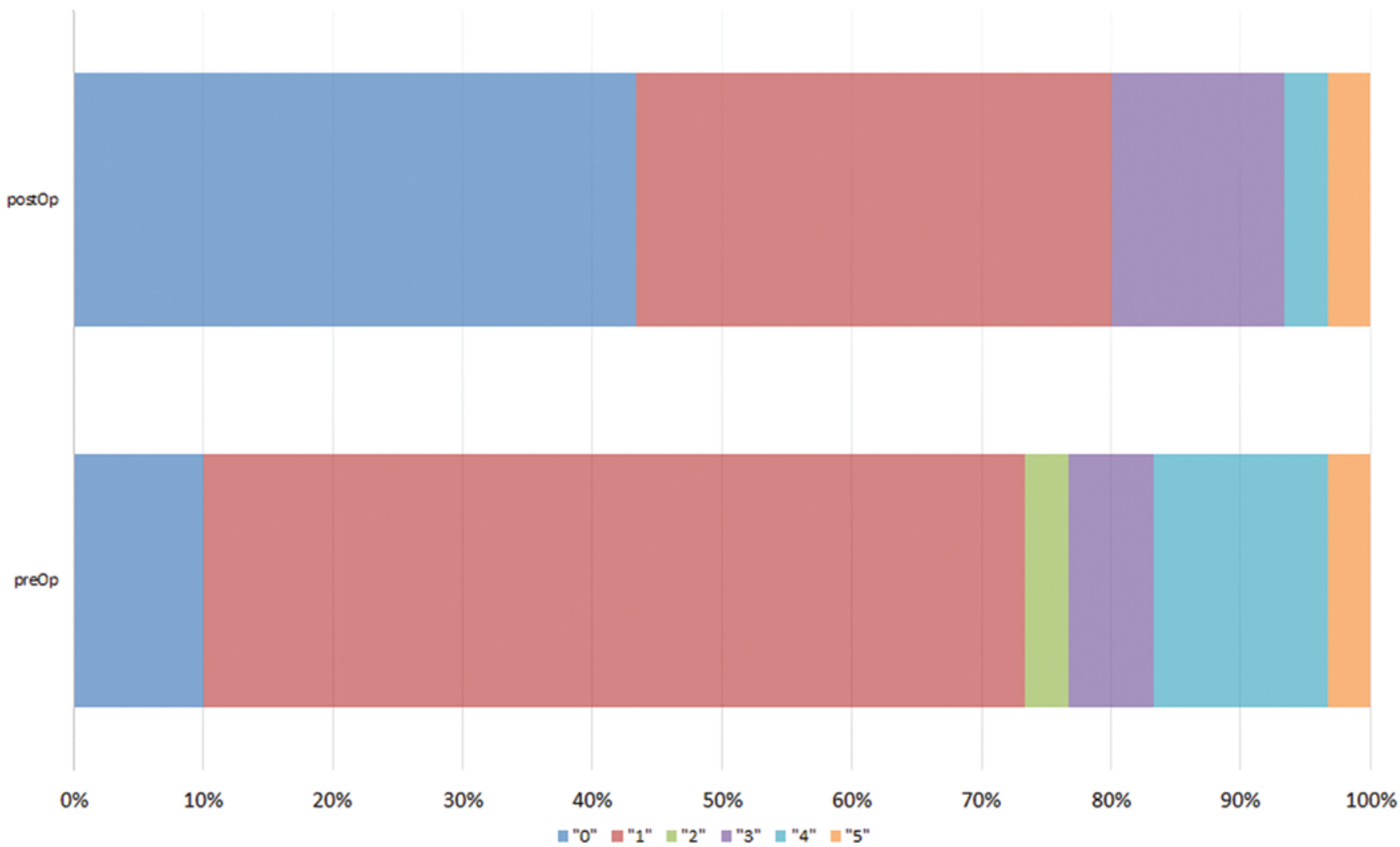

FIG. 6. Graphs showing preoperative and postoperative mRS scores for the 30 patients with a complex MCA aneurysm. Figure is available in color online only.

which enables the 1 bypass to retrograde fill the aneurysm and supply the unbypassed efferent trunk or trunks. Retrograde filling of a ruptured aneurysm is not advisable, because the aneurysm can re-rupture even though the inflow is occluded and reversed flow through the aneurysm is reduced. Exceptions to this algorithm occurred when a major trunk was already occluded with preexisting ischemic injury, and the reduced revascularization requirements of a single trunk were met with a low-flow STA-MCA bypass or an IC-IC bypass (Fig. 7).

\section{Postbifurcation MCA Aneurysms}

The strategy for postbifurcation MCA aneurysms is determined by their location along the MCA circulation (Fig. 2). Proximal insular $\left(\mathrm{M}_{2}\right.$ segment) aneurysms are accessible through a transsylvian approach that splits the Sylvian fissure and exposes the limen insulae. Similarly, opercular $\left(\mathrm{M}_{3}\right.$ segment) aneurysms are accessible through a distal transsylvian approach that opens the operculum. The accessibility of the proximal Sylvian fissure and the superficiality of the operculum make proximal insular (Fig. 10) and opercular MCA (Fig. 11) aneurysms, respectively, amenable to trapping and to all of the different bypass types, with the exception of the EC-IC interpositional bypass, because a distal efferent artery does not require high flow (Table 6). Reanastomosis was the most common technique, used in more than one-third of these patients by reconstructing the simple distal aneurysm with a single afferent and efferent artery without needing another donor artery or harvesting a scalp artery. Successful primary reanastomosis requires the same technical considerations discussed for prebifurcation aneurysms: redundancy of parent arteries, mobilization of the transected ends, complete excision of abnormal arterial tissues, and tension-free reanastomosis. Compared with prebifurcation aneurysms, postbifurcation aneurysms result in a higher success rate when primary reanastomosis is performed because these aneurysms tend to be smaller and have excisional gaps that are easier to bridge. Other IC-IC options involve an adjacent donor artery that makes for a more complex reconstruction. Reanastomoses were performed both deep in the Sylvian fissure and shallow in the operculum. In situ bypass, reimplantation, and interpositional bypass were used when aneurysm size or complexities prevented an easy end-to-end reanastomosis. Postbifurcation MCA aneurysms at significant branch points with 2 efferent arteries require a combination bypass.

In contrast to proximal insular and opercular MCA aneurysms, distal insular ( $\mathbf{M}_{2}$ segment) aneurysms are much less accessible and more difficult to visualize, because efferent arteries are buried deep in the insular recess. Instead of trapping/excision and IC-IC bypass, these aneurysms are treated with proximal occlusion and STA-MCA bypass (Fig. 12). These aneurysms were common, accounting for more than one-third of postbifurcation MCA an- 


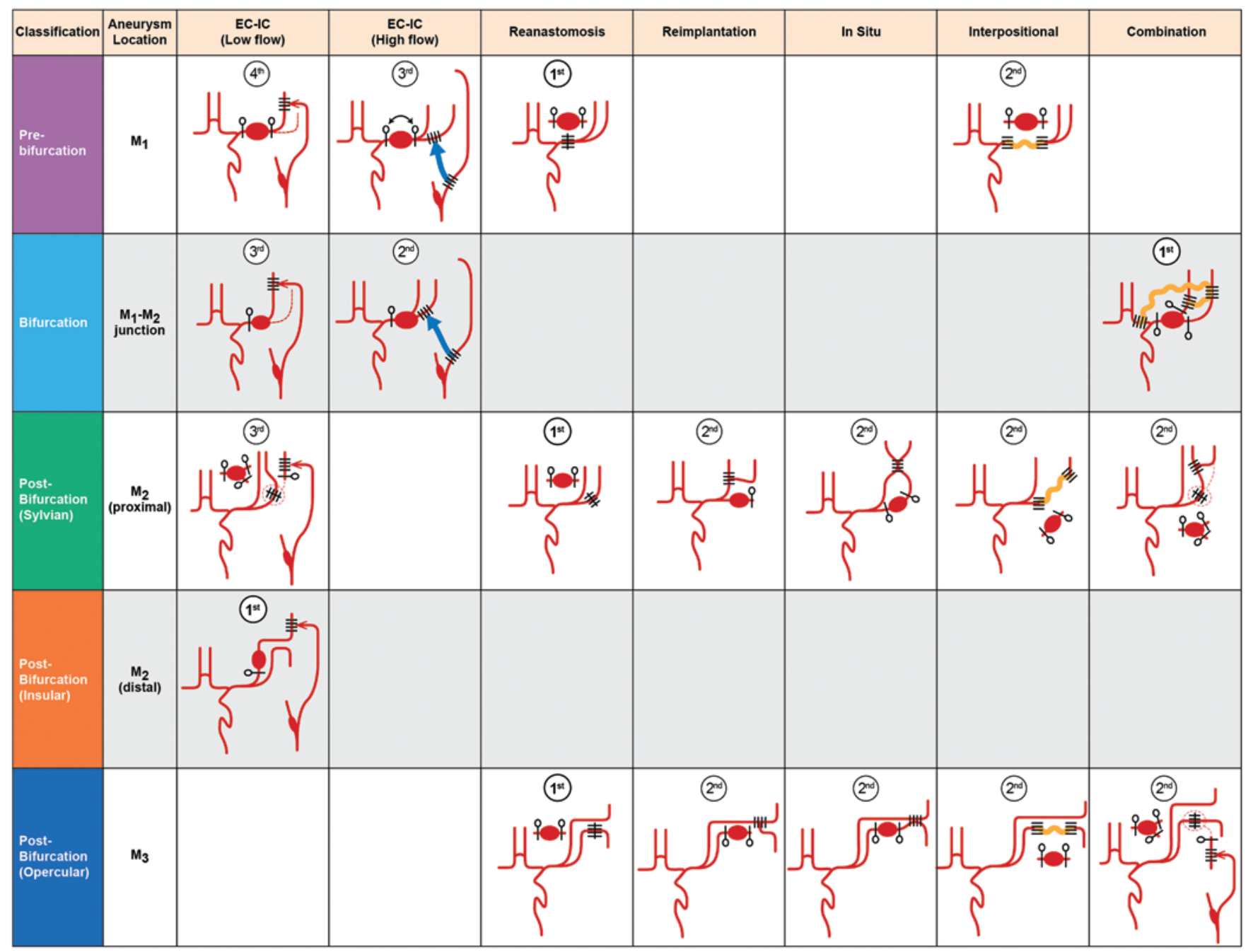

FIG. 7. Summary of bypass options according to $5 \mathrm{MCA}$ aneurysm locations and 7 types of bypasses. $M_{1}, M_{2}$, and $M_{3}$ refer to the segmental anatomy of the MCA; 1st, 2nd, 3rd, and 4th refer to the preferred choices for bypass options. Figure is available in color online only.

eurysms. An STA-MCA bypass to a cortical $\mathrm{M}_{4}$ recipient is ideal, because the distal Sylvian fissure can be difficult to split and is surrounded by Broca and Wernicke speech areas in the dominant hemisphere. A superficial bypass and proximal occlusion using the flash fluorescence technique to identify the efferent artery on the cortical surface provide a simple strategy for managing these aneurysms. Postbifurcation MCA aneurysms, unlike the other MCA aneurysms, are not associated with LSAs, which simplifies their management.

\section{Strategic Planning}

Our strategic algorithm is meant to be simple and efficient, using the minimum number of bypasses and anastomoses while avoiding unnecessary effort. We do not use prophylactic or protective bypasses, which typically are STA-MCA bypasses performed to support the MCA territory during the installation of a high-flow bypass or during temporary occlusion for the intervention of some aneurysms. These protective bypasses require extra time and effort for bypasses that ultimately become unneces- sary. However, strategic planning should minimize overall ischemia time. The sequence and type (side to side, end to end, or end to side) of anastomoses can be modified to allow early reperfusion after completing an anastomosis (as with the double-reimplantation technique) or intermittent reperfusion between anastomoses (as with end-toside or side-to-side rather than end-to-end anastomoses). Bypass selection should also be adapted to the surgical conditions. For example, a double-reimplantation bypass with an $\mathrm{A}_{1}$ segment donor site might be inappropriate in a swollen brain after a high-grade $\mathrm{SAH}$, and a simpler combination bypass might be better. Our published results of IC-IC bypasses are comparable with those of EC-IC bypasses. ${ }^{4,17,18,21,44}$ Although we favor IC reconstructive techniques, conventional low- and high-flow EC-IC bypasses are essential for complex MCA aneurysms for several reasons. First, the large hemispheric territory supplied by the MCA requires high-flow replacement with prebifurcation aneurysms and EC contributions to combination bypasses with bifurcation aneurysms. Second, IC-IC bypasses are technically challenging, and EC-IC bypasses are a simpler 
Prebifurcation - MCA Aneurysm

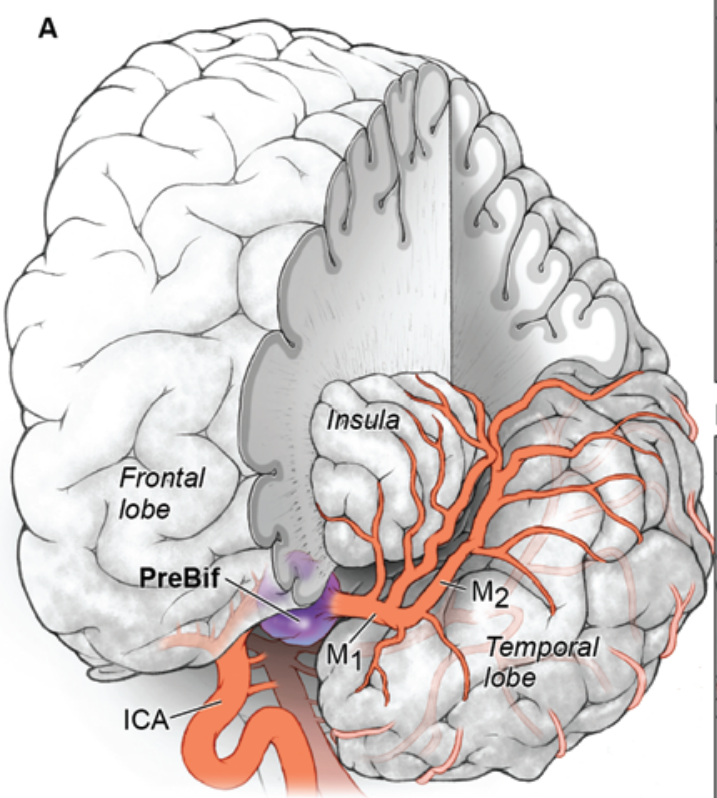

Reanastomosis

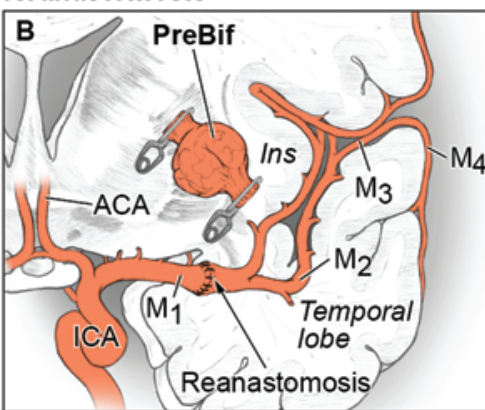

Interpositional

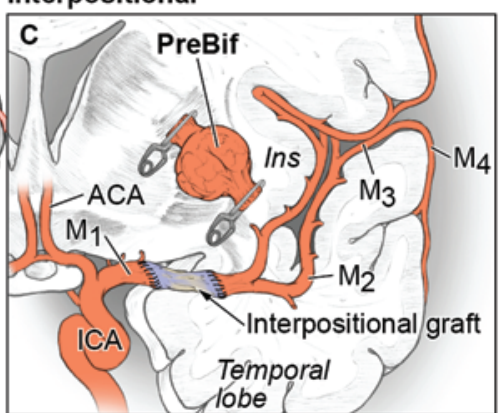

EC-IC (High Flow)

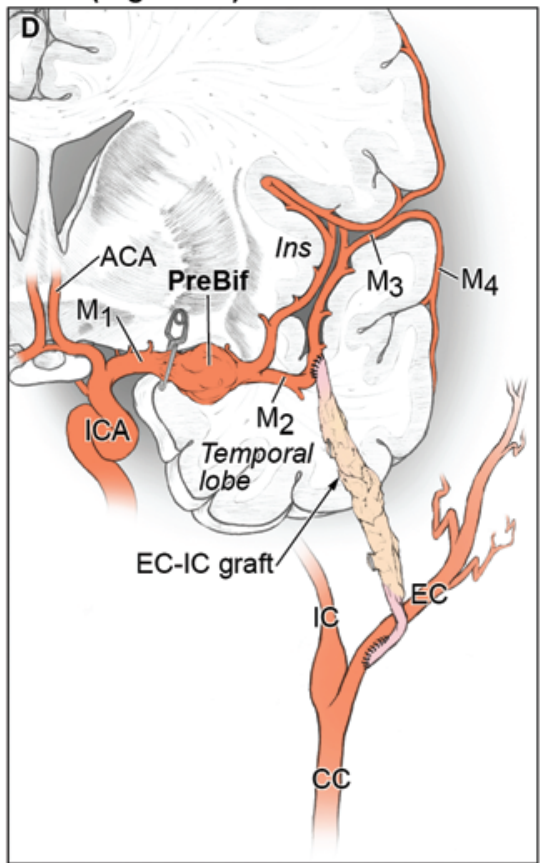

FIG. 8. Summary of bypass options for prebifurcation MCA aneurysms. As seen from an anterior oblique view (A) with the frontal lobe sectioned down to the insula. Reanastomosis (B), interpositional grafting (C), and EC-IC high-flow bypass (D) are shown in coronal cross-sectional views. $\mathrm{CC}=$ common carotid artery; Ins = insula. Copyright Michael Lawton. Published with permission. Figure is available in color online only.
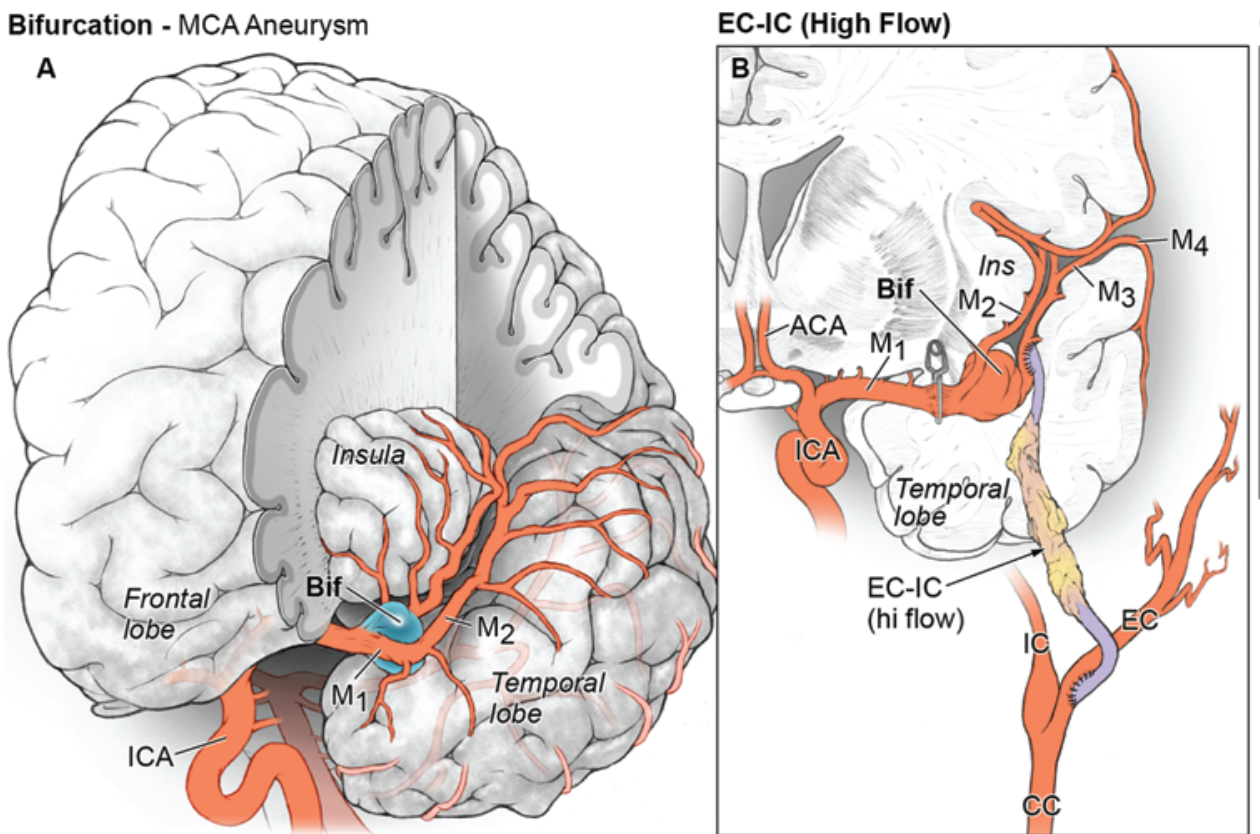

Combination

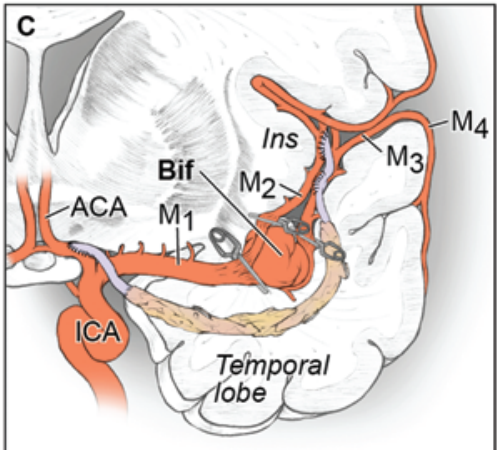

FIG. 9. Summary of bypass options for bifurcation MCA aneurysms. As seen from an anterior-oblique view $(\mathbf{A})$ with the frontal lobe sectioned down to the insula. EC-IC high-flow bypass $(B)$ and combination bypass $\left(A_{1}-M_{2}-M_{2}\right.$ double-reimplantation technique) (C) are shown in coronal cross-sectional views. Copyright Michael Lawton. Published with permission. Figure is available in color online only. 


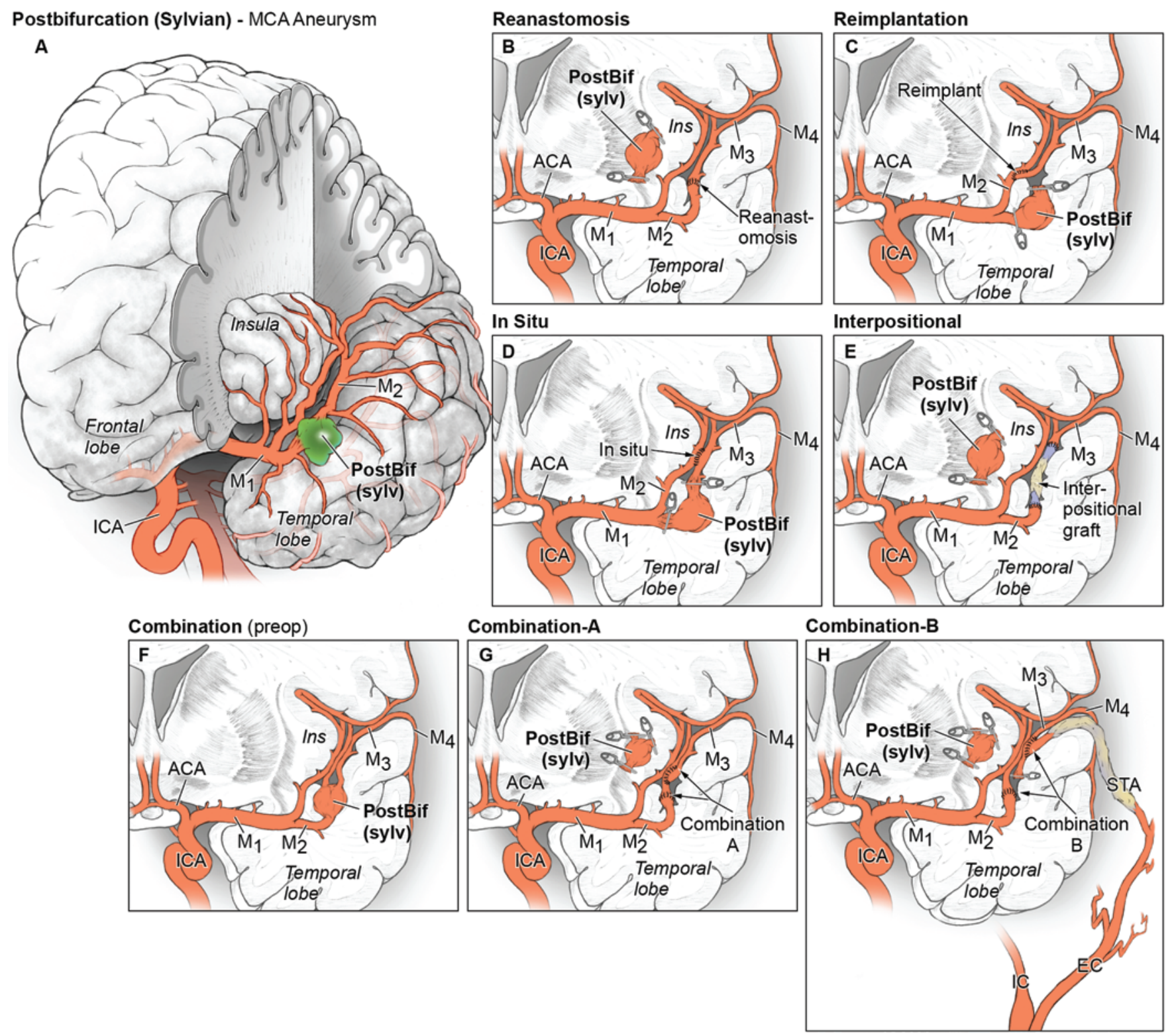

FIG. 10. Summary of bypass options for postbifurcation MCA aneurysms in the proximal insula or Sylvian fissure. As seen from an anterior oblique view $(\mathbf{A})$ with the frontal lobe sectioned down to the insula. Reanastomosis (B), reimplantation (C), in situ bypass $(\mathrm{D})$, interpositional bypass $(\mathrm{E})$, and combination bypasses $(\mathrm{F}-\mathrm{H})$ are shown in coronal cross-sectional views. Copyright Michael Lawton. Published with permission. Figure is available in color online only.

alternative. Third, anatomical constraints, such as those in the insular recess or when the ATA is not available as an IC donor, can limit IC-IC bypass options. Fourth, IC-IC bypass can require temporary occlusion of an uninvolved donor artery and confer additional ischemic risk, which might not be advisable for patients in critical condition.

Many of our reconstructive designs were based on arterial anatomy rather than quantitative blood flow measurements. Bypasses were selected to replace flow after deliberate arterial sacrifice based on the caliber of the occluded artery and the size of the associated territory. High-flow bypasses were selected for proximal arteries with large diameters, whereas low-flow bypasses were selected for distal arteries with small diameters. In addition, single high-flow bypasses were selected to revascularize multiple distal branches, such as after obliteration of a prebifurcation or bifurcation aneurysm. We did not use quantitative Doppler ultrasonography intraoperatively as part of our bypass selection, and balloon temporary occlusion did not affect our strategies. Our results with this anatomical approach compare favorably to those of other series in which quantitative techniques were used., ${ }^{4,51}$

\section{Limitations}

The algorithm discussed here is proposed as a guide for surgical planning and decision-making, but it is no substitute for individualized management and creative innovation. Some aneurysms might not fit our classification or 
Postbifurcation (Opercular) - MCA Aneurysm

A

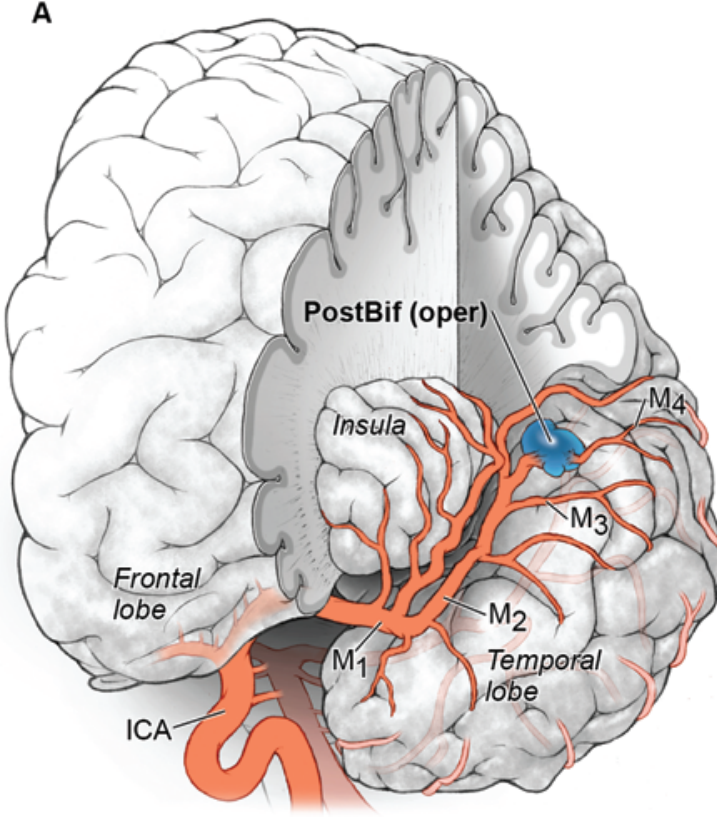

Reanastomosis

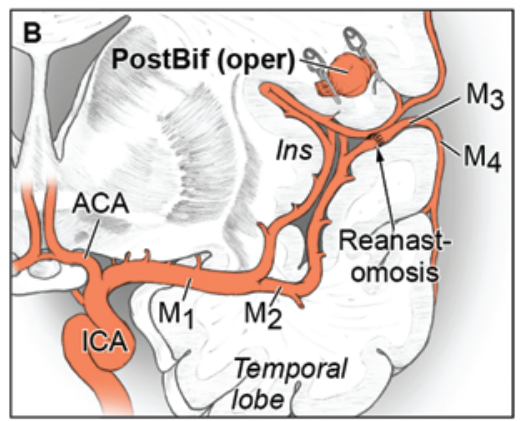

In Situ

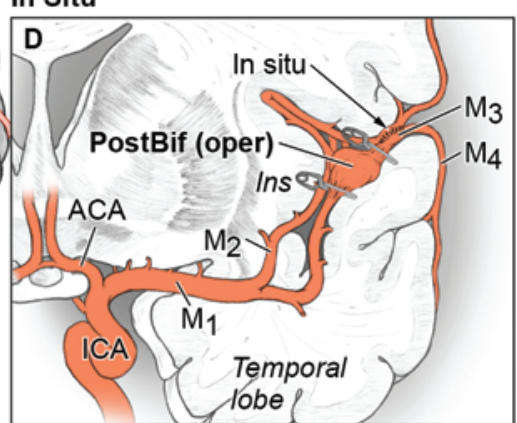

Reimplantation

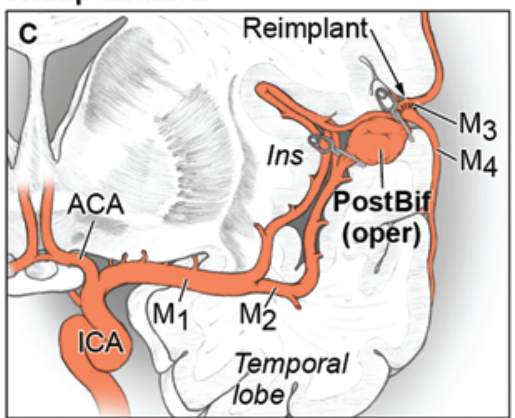

Interpositional

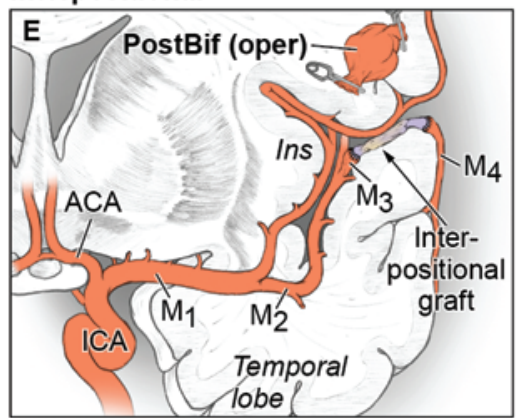

FIG. 11. Summary of bypass options for postbifurcation MCA aneurysms in the operculum. As seen from an anterior oblique view (A) with the frontal lobe sectioned down to the insula. Reanastomosis (B), reimplantation (C), in situ bypass (D), and interpositional bypass $(\mathrm{E})$ are shown in coronal cross-sectional views. Copyright Michael Lawton. Published with permission. Figure is available in color online only.
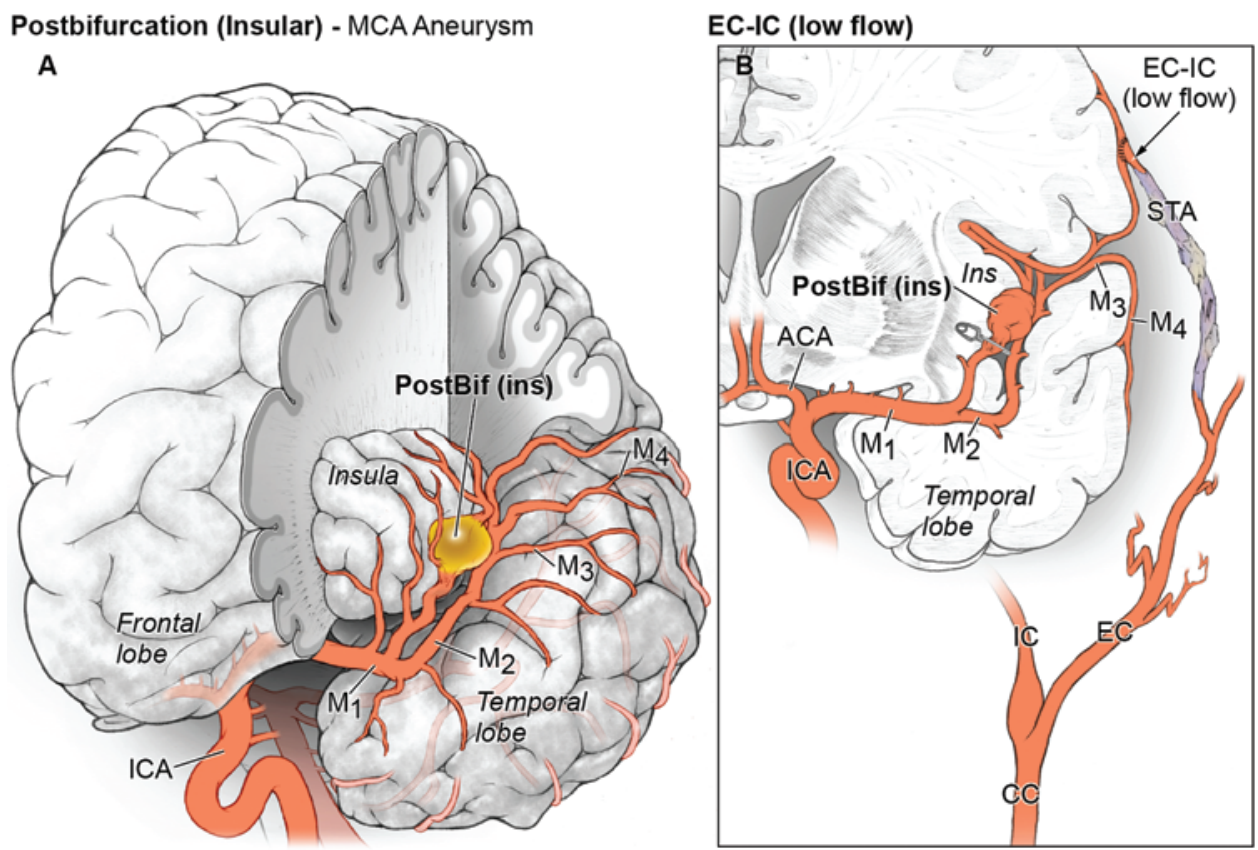

FIG. 12. Summary of bypass options for postbifurcation MCA aneurysms in the distal insula. A: As seen from an anterior oblique view with the frontal lobe sectioned down to the insula. B: An STA-MCA bypass is shown in a coronal cross-sectional view. Copyright Michael Lawton. Published with permission. Figure is available in color online only.

might not be treated best with our approach. These strategies are based on a small cohort of patients with inherent referral and selection biases. The algorithm embodies our preference for IC-IC bypasses, which we like for their el- egance, their prevention of additional cervical incisions, their shorter graft lengths and higher patency in the long term, and less vulnerability and for their lack of requirement for harvesting an EC donor artery. Figure 7 shows a 
comprehensive summary of available bypass options, and the preferred choices reflect the thinking of our team and our experiences over many years. However, these choices are not absolute recommendations, and those who make final decisions must account for patient presentation, specific aneurysm anatomy, relative risks, and surgeon ability. For example, we prefer reanastomosis (first choice) for a prebifurcation MCA aneurysm that does not incorporate perforators, because it reconstructs the parent artery with a single short suture line, but a simple STA-MCA bypass (fourth choice) might also work well. Future studies with more patients are needed to define the best choice of bypass for each pathological entity.

\section{Conclusions}

The management of complex MCA aneurysms can be challenging. Many of these aneurysms cannot be clipped and require exclusion from the circulation in combination with a revascularization strategy to re-perfuse the territory supplied by the excluded parent artery. Variations in segmental MCA anatomy preclude a uniform bypass strategy for all MCA aneurysms. Prebifurcation, bifurcation, and postbifurcation MCA aneurysms present different surgical challenges that must be individualized to specific patient anatomy and clinical status. Our proposed algorithm might assist in surgical planning for complex MCA aneurysms by providing a comprehensive yet flexible strategy for selecting the optimal bypass and occlusion technique according to aneurysm location relative to the MCA bifurcation. The proposed algorithm is intended only as a guide for surgical therapy and will need to be adapted as novel endovascular treatments become available.

\section{References}

1. Abla AA, Lawton MT: Anterior cerebral artery bypass for complex aneurysms: an experience with intracranial-intracranial reconstruction and review of bypass options. J Neurosurg 120:1364-1377, 2014

2. Blackburn SL, Abdelazim AM, Cutler AB, Brookins KT, Fargen KM, Hoh BL, et al: Endovascular and surgical treatment of unruptured MCA aneurysms: meta-analysis and review of the literature. Stroke Res Treat 2014:348147, 2014

3. Bojanowski WM, Spetzler RF, Carter LP: Reconstruction of the MCA bifurcation after excision of a giant aneurysm. Technical note. J Neurosurg 68:974-977, 1988

4. Cantore G, Santoro A, Guidetti G, Delfinis CP, Colonnese C, Passacantilli E: Surgical treatment of giant intracranial aneurysms: current viewpoint. Neurosurgery 63 (4 Suppl 2):279-290, 2008

5. Cruz JP, O'Kelly C, Kelly M, Wong JH, Alshaya W, Martin A, et al: Pipeline embolization device in aneurysmal subarachnoid hemorrhage. AJNR Am J Neuroradiol 34:271276, 2013

6. Davies JM, Lawton MT: Advances in open microsurgery for cerebral aneurysms. Neurosurgery 74 (Suppl 1):S7-S16, 2014

7. Davies JM, Lawton MT: "Picket fence" clipping technique for large and complex aneurysms. Neurosurg Focus 39 (Video Suppl 1):V17, 2015

8. Diaz FG, Umansky F, Mehta B, Montoya S, Dujovny M, Ausman JI, et al: Cerebral revascularization to a main limb of the middle cerebral artery in the Sylvian fissure. An alternative approach to conventional anastomosis. J Neurosurg 63:2129, 1985
9. Diaz OM, Rangel-Castilla L, Barber S, Mayo RC, Klucznik R, Zhang YJ: Middle cerebral artery aneurysms: a singlecenter series comparing endovascular and surgical treatment. World Neurosurg 81:322-329, 2014

10. D’Urso PI, Lanzino G, Cloft HJ, Kallmes DF: Flow diversion for intracranial aneurysms: a review. Stroke 42:2363-2368, 2011

11. Fulkerson DH, Voorhies JM, Payner TD, Leipzig TJ, Horner TG, Redelman K, et al: Middle cerebral artery aneurysms in children: case series and review. J Neurosurg Pediatr 8:79-89, 2011

12. Greene KA, Anson JA, Spetzler RF: Giant serpentine middle cerebral artery aneurysm treated by extracranial-intracranial bypass. Case report. J Neurosurg 78:974-978, 1993

13. Hasegawa Y, Morioka M, Makino K, Kai Y, Hamada J, Kuratsu J: Arterial graft to treat ruptured distal middle cerebral artery aneurysms in a patient with mucosa-associated lymphoid tissue lymphoma. Case report. Neurol Med Chir (Tokyo) 52:443-445, 2012

14. Hrbác T, Drábek P, Klement P, Procházka V: A combined approach to treatment of the dissecting middle cerebral artery fusiform aneurysm. A case report. Interv Neuroradiol 15:349-354, 2009

15. Irie T, Yoshitani K, Ohnishi Y, Shinzawa M, Miura N, Kusaka Y, et al: The efficacy of motor-evoked potentials on cerebral aneurysm surgery and new-onset postoperative motor deficits. J Neurosurg Anesthesiol 22:247-251, 2010

16. Jabbour P, Chalouhi N, Tjoumakaris S, Gonzalez LF, Dumont AS, Randazzo C, et al: The Pipeline Embolization Device: learning curve and predictors of complications and aneurysm obliteration. Neurosurgery 73:113-120, 2013

17. Kalani MY, Ramey W, Albuquerque FC, McDougall CG, Nakaji P, Zabramski JM, et al: Revascularization and aneurysm surgery: techniques, indications, and outcomes in the endovascular era. Neurosurgery 74:482-498, 2014

18. Kalani MY, Zabramski JM, Hu YC, Spetzler RF: Extracranial-intracranial bypass and vessel occlusion for the treatment of unclippable giant middle cerebral artery aneurysms. Neurosurgery 72:428-436, 2013

19. Kivipelto L, Niemelä M, Meling T, Lehecka M, Lehto H, Hernesniemi J: Bypass surgery for complex middle cerebral artery aneurysms: impact of the exact location in the MCA tree. J Neurosurg 120:398-408, 2014

20. Lawton MT: Seven Aneurysms: Tenets and Techniques for Clipping. New York: Thieme, 2010

21. Lawton MT, Hamilton MG, Morcos JJ, Spetzler RF: Revascularization and aneurysm surgery: current techniques, indications, and outcome. Neurosurgery 38:83-94, 1996

22. Lawton MT, Quiñones-Hinojosa A: Double reimplantation technique to reconstruct arterial bifurcations with giant aneurysms. Neurosurgery 58 (4 Suppl 2):ONS-347-ONS-353, 2006

23. Lawton MT, Quiñones-Hinojosa A, Chang EF, Yu T: Thrombotic intracranial aneurysms: classification scheme and management strategies in 68 patients. Neurosurgery 56:441-454, 2005

24. Mrak G, Paladino J, Stambolija V, Nemir J, Sekhar LN: Treatment of giant and large fusiform middle cerebral artery aneurysms with excision and interposition radial artery graft in a 4-year-old child: case report. Neurosurgery 10 (Suppl 1):E172-E177, 2014

25. Mura J, Torche E, Riquelme F, Parra M, Julio R: Three-yearold patient with giant MCA aneurysm treated by trappingresection plus STA-MCA bypass. Case report. Childs Nerv Syst 28:169-173, 2012

26. Nakahara I, Taha MM, Higashi T, Iwamuro Y, Iwaasa M, Watanabe Y, et al: Different modalities of treatment of intracranial mycotic aneurysms: Report of 4 cases. Surg Neurol 66:405-410, 2006 
27. Narata AP, Yilmaz H, Schaller K, Lovblad KO, Pereira VM: Flow-diverting stent for ruptured intracranial dissecting aneurysm of vertebral artery. Neurosurgery 70:982-989, 2012

28. Newell DW, Skirboll SL: Revascularization and bypass procedures for cerebral aneurysms. Neurosurg Clin N Am 9:697-711, 1998

29. Nussbaum L, Defillo A, Zelensky A, Nussbaum ES: A short segment intracranial-intracranial jump graft bypass followed by proximal arterial occlusion for a distal MCA aneurysm. Surg Neurol Int 2:98, 2011

30. Quiñones-Hinojosa A, Du R, Lawton MT: Revascularization with saphenous vein bypasses for complex intracranial aneurysms. Skull Base 15:119-132, 2005

31. Quiñones-Hinojosa A, Lawton MT: In situ bypass in the management of complex intracranial aneurysms: technique application in 13 patients. Neurosurgery 57 (1 Suppl):140-145, 2005

32. Rodríguez-Hernández A, Sughrue ME, Akhavan S, Habdank-Kolaczkowski J, Lawton MT: Current management of middle cerebral artery aneurysms: surgical results with a "clip first" policy. Neurosurgery 72:415-427, 2013

33. Saito H, Ogasawara K, Kubo Y, Saso M, Otawara Y, Ogawa A: Treatment of ruptured spontaneous saccular aneurysm in the central artery of the middle cerebral artery using bypass surgery combined with trapping-case report. Neurol Med Chir (Tokyo) 47:471-474, 2007

34. Sakamoto S, Ikawa F, Kawamoto H, Ohbayashi N, Inagawa T: Acute surgery for ruptured dissecting aneurysm of the M3 portion of the middle cerebral artery. Neurol Med Chir (Tokyo) 43:188-191, 2003

35. Sanai N, Auguste KI, Lawton MT: Microsurgical management of pediatric intracranial aneurysms. Childs Nerv Syst 26:1319-1327, 2010

36. Sanai N, Quinones-Hinojosa A, Gupta NM, Perry V, Sun PP, Wilson $\mathrm{CB}$, et al: Pediatric intracranial aneurysms: durability of treatment following microsurgical and endovascular management. J Neurosurg 104 (2 Suppl):82-89, 2006

37. Sanai N, Zador Z, Lawton MT: Bypass surgery for complex brain aneurysms: an assessment of intracranial-intracranial bypass. Neurosurgery 65:670-683, 2009

38. Sekhar LN, Stimac D, Bakir A, Rak R: Reconstruction options for complex middle cerebral artery aneurysms. Neurosurgery 56 (1 Suppl):66-74, 2005

39. Seo BR, Kim TS, Joo SP, Lee JM, Jang JW, Lee JK, et al: Surgical strategies using cerebral revascularization in complex middle cerebral artery aneurysms. Clin Neurol Neurosurg 111:670-675, 2009

40. Siddiqui AH, Abla AA, Kan P, Dumont TM, Jahshan S, Britz $\mathrm{GW}$, et al: Panacea or problem: flow diverters in the treatment of symptomatic large or giant fusiform vertebrobasilar aneurysms. J Neurosurg 116:1258-1266, 2012

41. Siddiqui AH, Kan P, Abla AA, Hopkins LN, Levy EI: Complications after treatment with pipeline embolization for giant distal intracranial aneurysms with or without coil embolization. Neurosurgery 71:E509- E513, 2012

42. Smith TR, Cote DJ, Dasenbrock HH, Hamade YJ, Zammar SG, El Tecle NE, et al: Comparison of the efficacy and safety of endovascular coiling versus microsurgical clipping for unruptured middle cerebral artery aneurysms: a systematic review and meta-analysis. World Neurosurg 84:942-953, 2015
43. Spetzler RF, Carter LP: Revascularization and aneurysm surgery: current status. Neurosurgery 16:111-116, 1985

44. Sughrue ME, Saloner D, Rayz VL, Lawton MT: Giant intracranial aneurysms: evolution of management in a contemporary surgical series. Neurosurgery 69:1261-1271, 2011

45. van Doormaal TP, van der Zwan A, Verweij BH, Han KS, Langer DJ, Tulleken CA: Treatment of giant middle cerebral artery aneurysms with a flow replacement bypass using the excimer laser-assisted nonocclusive anastomosis technique. Neurosurgery 63:12-22, 2008

46. van Rooij WJ, Bechan RS, Peluso JP, Sluzewski M: Endovascular treatment of intracranial aneurysms in the flow diverter era: frequency of use and results in a consecutive series of 550 treatments in a single centre. Interv Neuroradiol 20:428-435, 2014

47. Walcott BP, Pisapia JM, Nahed BV, Kahle KT, Ogilvy CS: Early experience with flow diverting endoluminal stents for the treatment of intracranial aneurysms. J Clin Neurosci 18:891-894, 2011

48. Weinzierl MR, Reinacher P, Gilsbach JM, Rohde V: Combined motor and somatosensory evoked potentials for intraoperative monitoring: intra- and postoperative data in a series of 69 operations. Neurosurg Rev 30:109-116, 2007

49. Yang I, Lawton MT: Clipping of complex aneurysms with fenestration tubes: application and assessment of three types of clip techniques. Neurosurgery 62 (5 Suppl 2):ONS371ONS379, 2008

50. Zhang YJ, Barrow DL, Day AL: Extracranial-intracranial vein graft bypass for giant intracranial aneurysm surgery for pediatric patients: two technical case reports. Neurosurgery 50:663-668, 2002

51. Zhu W, Liu P, Tian Y, Gu Y, Xu B, Chen L, et al: Complex middle cerebral artery aneurysms: a new classification based on the angioarchitecture and surgical strategies. Acta Neurochir (Wien) 155:1481-1491, 2013

\section{Disclosures}

The authors report no conflict of interest concerning the materials or methods used in this study or the findings specified in this paper.

\section{Author Contributions}

Conception and design: Lawton. Acquisition of data: Lawton, Tayebi Meybodi, Huang. Analysis and interpretation of data: all authors. Drafting the article: Lawton, Tayebi Meybodi. Critically revising the article: Lawton, Tayebi Meybodi, Huang, Benet. Reviewed submitted version of manuscript: all authors. Approved the final version of the manuscript on behalf of all authors: Lawton. Statistical analysis: Lawton, Tayebi Meybodi, Huang. Administrative/technical/material support: Lawton. Study supervision: Lawton.

\section{Correspondence}

Michael T. Lawton, Department of Neurosurgery, University of California, San Francisco, 505 Parnassus Ave., M780, San Francisco, CA 94143. email: michael.lawton@ucsf.edu. 